Portland State University

PDXScholar

$1-1-2011$

\title{
Postfledging Survival and Habitat Use of Spotted Towhees (Pipilo maculatus) in an Urban Park
}

Amy Ann Shipley

Portland State University

Follow this and additional works at: https://pdxscholar.library.pdx.edu/open_access_etds

Part of the Poultry or Avian Science Commons

Let us know how access to this document benefits you.

Recommended Citation

Shipley, Amy Ann, "Postfledging Survival and Habitat Use of Spotted Towhees (Pipilo maculatus) in an Urban Park" (2011). Dissertations and Theses. Paper 16.

https://doi.org/10.15760/etd.16

This Thesis is brought to you for free and open access. It has been accepted for inclusion in Dissertations and Theses by an authorized administrator of PDXScholar. Please contact us if we can make this document more accessible: pdxscholar@pdx.edu. 
Postfledging Survival and Habitat Use of Spotted Towhees (Pipilo maculatus) in an

\section{Urban Park}

by

Amy Ann Shipley

A thesis submitted in partial fulfillment of the requirements for the degree of

Master of Science

in

Biology

Thesis Committee:

Michael T. Murphy, Chair

Suzanne Estes

J. Alan Yeakley

Portland State University

(C)2011 


\section{Abstract}

Habitat fragmentation, and the resulting increase in edge habitat, has important effects on birds, including the increased probability of nest predation, changes in habitat structure, and the increased presence of non-native plant species. It is critical to understand the effects of fragmentation at all stages of the avian life cycle, including the often overlooked postfledging period. Because much of juvenile mortality occurs during the immediate postfledging period, and juvenile mortality contributes substantially to population dynamics, it is necessary to understand if fledgling survival is reduced in edge habitats and if fledglings' survival is influenced by their habitat use. During 2008 and 2009 I radio-tracked 52 fledgling Spotted Towhees (Pipilo maculatus) during the 30-day postfledging period in a 24-ha urban park near Portland, Oregon. Thirty-six fledglings (69\%) survived the 27 -day tracking period (an estimated $62.1 \%$ survived the entire 30 day postfledging period). At least 9 of 16 predation events were attributable to domestic cats (Felis domesticus) or Western Screech-owls (Megascops kennicottii). Although fledglings were more likely to be found near edges than the park interior, fledglings located closer to park edges had a higher probability of dying. However, I found that towhee nests were more likely to be found near edges, nests near edges produced more fledglings, and nestlings near edges were heavier. I used a STELLA-based stochastic model of nest success and fledgling survival to show that the benefits initially gained by nesting near edges were reversed during the postfledging period. The number of fledglings per nest that survived to the end of the 30-day postfledging period was significantly lower near edges than in the park interior. This apparent preference for 
nesting near edges, paired with higher fledgling mortality near edges, is consistent with the idea that edges are ecological traps.

Fledgling habitat was significantly more structurally dense and had a greater abundance of non-native plant species, particularly Himalayan Blackberry (Rubus armeniacus), than nest habitat. Towhees avoided English Ivy (Hedera helix) for both nesting and care of fledglings. However, fledgling survival was not related to vegetation characteristics, which suggests that increased fledgling mortality near edges was a direct result of increased predator abundance or predation near edges, and was not an artifact of changes in habitat near edges. My results help to establish that fledgling survival and the unique habitat requirements of fledglings should be considered along with nest success and nest habitat when examining the effects of habitat fragmentation on bird populations. More broadly, this study has important implications for conservation, as it exemplifies how phenomena such as ecological traps created by anthropogenic changes in the environment can be overlooked if only one life history stage is studied. 


\section{ACKnOWledgments}

This research would not have been possible without the dedicated efforts of many people. Sarah Bartos Smith, Jennifer McKay, and Jennifer Richardson gave me the idea to study Spotted Towhee fledglings in Springbrook Park and provided very helpful advice about finding towhee nests, attaching transmitters, and about the banded towhee population. Jennifer McKay mapped the park perimeter and trails and gave me advice about how to work with the positional data in ArcGIS. Luke Redmond provided a taxidermic towhee mount and demonstrated its use for target mist-netting of male towhees.

Several loyal field assistants donated many hours of their time to this project, particularly Adam Elzinga, Heather Radke Ogawa, Laura Barrow, Jenny Kinder, and Zach Holmboe, and I am indebted to them for their service. They assisted with mistnetting, nest-searching, nest checks, radio-tracking, vegetation surveys, and many other vital tasks. Zach offered many useful tips about plant identification. Heather was always cheerful and kept our spirits up through many long days of vegetation surveys.

Beyond putting in just as many hours as I did for day-to-day fieldwork, Adam single-handedly devised many of the techniques that made this project possible. He replaced batteries on all the transmitters multiple times throughout the seasons so they could be reused at a fraction of the cost, drastically increasing the number of fledglings that we tracked. Adam recorded an audio clip of a fledgling distress call and came up with the idea of using it to lure female towhees into a mist-net for banding. Setting up mist-nets at night around sleeping fledglings to capture them at the end of the 
postfledging period was also his idea. Adam also devoted many hours to data organization. I cannot thank him enough for all that he has done.

Many thanks go to Michael Murphy, my advisor, for providing guidance and encouragement throughout the entire process. He gave me lots of useful advice for planning the study's design and implementation, and spent many hours pouring over the data and discussing with me the best approaches for statistical analysis. Finally, this manuscript benefited greatly from his many careful critiques of my writing and presentation.

I also extend my gratitude to my committee members, Suzanne Estes and Alan Yeakley, for their advice and helpful suggestions for editing this thesis. 


\section{TABLE OF CONTENTS}

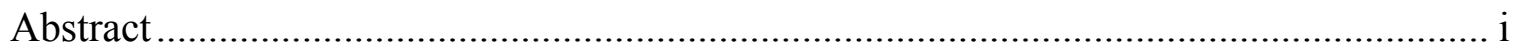

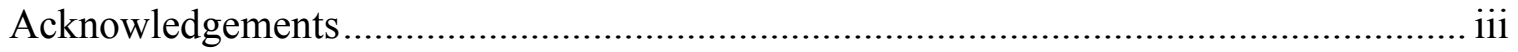

List of Tables .................................................................................................. vi

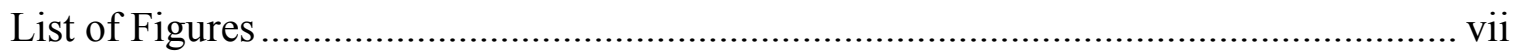

Chapter 1:

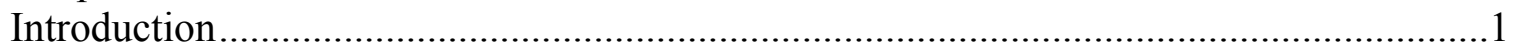

Chapter 2:

Postfledging survival of Spotted Towhees (Pipilo maculatus) near urban park edges:

evidence for an ecological trap

Chapter 3:

Habitat use of postfledging Spotted Towhees (Pipilo maculatus) in an urban park ........45

Chapter 4:

Conclusions.....

References 


\section{LIST OF TABLES}

Table 2.1. Numbers of Spotted Towhee fledglings killed by different predators during the first four weeks post-fledging.....

Table 2.2. Survival rates and predators of bird species during the first 30 days postfledging in different habitats....

Table 2.3. The average number of Spotted Towhee fledglings per nest alive 30 days post-fledging at varying distances to park edge

Table 3.1. Principal components and factor loadings for habitat variables measured during vegetation surveys of Spotted Towhee nests, Spotted Towhee fledgling

locations, and random locations

Table 3.2. Results of ANOVAs that compared habitats used by Spotted Towhees for nest placement, fledgling locations, and random locations, and results of $t$-tests that compared successful and failed nest locations and surviving and nonsurviving fledgling locations for five principal components that summarize habitat variables 


\section{LIST OF FigURES}

Figure 2.1. Map of successful and failed Spotted Towhee nests in Springbrook Park.....38

Figure 2.2. The relationship between the number of Spotted Towhee fledglings produced per successful nest and the distance from the nest to the nearest urban park edge

Figure 2.3. The relationship between mean nestling mass and the distance from the nest to the nearest urban park edge .40

Figure 2.4. Map of daily radio telemetry locations of all Spotted Towhee fledglings that survived the postfledging period and that died during the postfledging period in an urban park.

Figure 2.5. Cox proportional hazards regression for Spotted Towhee fledglings above and below the median fledgling distance to urban park edge

Figure 2.6. Cox proportional hazards regression for Spotted Towhee fledglings within the lower $25 \%$, middle $50 \%$, and upper $25 \%$ fledgling distance to urban park edge categories

Figure 2.7. Cox proportional hazards regression for Spotted Towhee fledglings above and below the median fledgling distance to urban park trail

Figure 3.1. The relationships between five principal components that summarize habitat variables and distance to the nearest edge in an urban park.

Figure 3.2. Mean values of principal components 1-5 for Spotted Towhee nest locations, Spotted Towhee fledgling locations, and random locations in an urban park 


\section{CHAPTER 1: Introduction}

Worldwide, the human population is expected to reach 7 billion in 2011, and climb to 9 billion by 2050. Much of the growth seen over the past 50 years can be attributed to increases in life expectancy in developing countries resulting from advances in public health and medicine (United Nations Population Division 2011). Over half of the world's population now lives in cities and towns, and this figure is expected to rise to almost $70 \%$ in 2050. In North America and Latin America, the proportion of people living in urban areas is the highest in the world: $80-82 \%$, with an expected increase to 89 90\% by 2050 (United Nations Population Division 2011).

Urban expansion and the resulting loss and fragmentation of habitats have important effects on many species. In a review of the effects of urbanization on plants and animals, McKinney (2008) found that for mammals, reptiles, amphibians, invertebrates, and plants, species richness was reduced in core urban environments. The majority of studies of animals also found that species richness decreased with moderate urbanization (McKinney 2008). Marzluff (2001) reviewed the effects of urbanization on birds and found less consistent results. The most consistent effects of increasing settlement were increases in non-native birds, birds that can nest on buildings, and decreases in ground-nesting and species that occupy the interior of native habitat. Urbanization may even benefit some bird species that have less specific habitat needs and can use human-supplemented food to survive the winter (Marzluff 2001). Urban growth is only one of multiple contributors to habitat loss, but it is an ongoing and widespread phenomenon that is expected to continue into the future (United Nations 2010a, b). It is thus important that we develop a better understanding of how urban fragmentation affects 
species because an enhanced ability to identify the features of remaining habitats that are most important to sustain species will help to determine if highly fragmented urban landscapes can support native populations.

In an increasingly urban world (Marzluff 2001), parks and greenspaces may play a key role in providing habitat to support native populations. On the other hand, parks and greenspaces may also function as ecological traps, a situation in which either settlement cues and/or habitat quality have changed such that animals seemingly prefer to use low-quality habitat (Gates and Gysel 1978, Robertson and Hutto 2006). Traditionally, high abundances and diversity of native species have been used to identify high-quality habitat (Marzluff 2001). However, relying solely on abundance to assess habitat quality for species can be misleading (Van Horne 1983) because high abundances need not translate into high reproductive success (Vickery et al. 1992). Reproductive success, and especially survival of adults and independent young, while more difficult to measure than abundance, are more reliable measures of habitat quality and population viability. This may be especially true in human-dominated landscapes because anthropogenically disturbed habitats often act as ecological traps (Bock and Jones 2004). Only by documenting reproductive success and survival is it possible to determine if parks and greenspaces function as quality habitat.

While birds face a variety of challenges in natural habitat, nest predation is widely recognized as the main cause of nest failure in birds (Ricklefs 1969, Martin 1993), and predation may be a particularly important factor influencing the productivity of birds in urban areas. For instance, as habitats become fragmented the proportion of the remaining habitat that becomes edge habitat inevitably increases. Urban parks and greenspaces are 
typically small and are often dissected by trails that may create edge effects in otherwise interior locations. Predator activity and/or abundance is often high near habitat edges (Donovan et al. 1997, Heske et al. 1999, Bolger 2002), habitat corridors (Sinclair et al. 2005), and trails (Miller and Hobbs 2000); consequently, it is not surprising that nest success is often lower near edges (Gates and Gysel 1978, Manolis et al. 2002) and in smaller habitat fragments (Andrén et al. 1985, Yahner and Scott 1988, Andrén 1992, Hinsley et al. 1999, Burke and Nol 2000, Zanette et al. 2000, Luck 2003). Moreover, nest predator abundance may be elevated in urban settings because of their release from predation by larger predators that generally disappear in small fragments (Crooks and Soulé 1999) and their ability to utilize resources inadvertently supplied by humans (Martin 1988, Haskell et al. 2001). Domestic cats (Felis domesticus) also pose a substantial threat to juvenile birds because cats are often highly abundant near residences and kill despite being well fed (by their owners). Cats may kill more juvenile birds than native predators (Balogh et al. 2011). Indeed, Crooks and Soulé (1999) found that cat abundance increased with decreasing fragment size, while Sinclair et al. (2005) determined that cats were more abundant in greenways with adjacent parking lots and roads. Balogh et al. (2011) also showed recently that cats were responsible for $47 \%$ of known predation events on fledgling Gray Catbirds (Dumatella carolinensis) in suburban areas (see also Baker et al. 2005). Thus, in parks and greenspaces that are adjacent to neighborhoods, cats may critically affect the sustainability of bird populations by preying on recently fledged and relatively immobile juvenile birds.

Historically, nearly all studies of avian reproductive success have been based on nest productivity (i.e., number of young to leave the nest), but as the Balogh et al. (2011) 
example showed, a complete accounting of reproductive success must also include survival until young become independent of their parents (Sullivan 1989). Hence, in recent years increasing numbers of studies have documented the survival of young in the postfledging period to better describe the vital rates that determine population viability. Sustainable populations, otherwise known as sources (Pulliam 1988), exist when local offspring production and survival is more than sufficient to offset adult mortality. Without measurement of reproductive success and survival it can be impossible to distinguish between population sources and sinks (i.e., offspring production and survival $<$ adult mortality) because immigration into sinks can prevent local extinction (Pulliam 1988). Identifying sources and sinks thus requires information on offspring production and subsequent survival of juveniles and adults. Of these, the survival of young between fledging and recruitment into the breeding population is the least well known. However, recent work on this issue suggests that mortality during the immediate postfledging period is likely much higher than what is experienced over the remainder of the year (e.g. Naef-Daenzer et al. 2001, Yackel Adams et al. 2001, Berkeley et al. 2007, Rush and Stutchbury 2008). In urban areas, the increased presence of predators near edges may unnaturally increase the already high mortality rates of fledgling birds.

In addition to changes in predation pressure in urban areas, the altered environment found in urban areas may present other potential challenges for young birds, such as changes in habitat structure and the increased presence of non-native and invasive plant species (Marzluff 2001, Smith et al. 2006) that may ultimately affect fledglings' ability to survive and contribute to the population growth of their species. Research on fledgling habitat use is relatively rare. In natural areas, young birds have been found in 
areas that differ in vegetation composition from that of the nest site (White et al. 2005, Rush and Stutchbury 2008, Vega Rivera et al. 1998), and these differences have also been associated with fledgling survival (King et al. 2006). However, it is virtually unknown how fledglings use habitat in urban areas and if it differs from that of the nest site. The increased presence of invasive plant species in urban areas (Marzluff 2001, Smith et al. 2006) can create ecological traps for nesting birds (Rodewald et al. 2010), but it is unclear how non-native vegetation interacts with the fledglings' ability to seek habitat that conceals them from predators, and if non-native vegetation is associated with fledgling survival (but see Ausprey and Rodewald 2011).

Here, I describe the results of my two-year study, which focused on measuring the postfledging survival and habitat use of the Spotted Towhee (Pipilo maculatus), a ground-nesting and ground-foraging songbird, in an urban park in the Portland, Oregon metropolitan region. In Chapter 2, I (1) present towhee survival rates during the immediate postfledging period, (2) document causes of death and discuss major predators of fledglings, (3) explore factors that may influence fledgling survival, particularly proximity to park edges and trails, and (4) present evidence that park edges are beneficial for towhees during the nesting period, but ultimately function as ecological traps for towhees. In Chapter 3, I take an in-depth look at fledgling habitat use, and (1) explore differences in vegetation characteristics, particularly structural density and the presence of non-native plant species, among randomly located points, habitat used by adults for nest placement, and by fledglings during the first two weeks out of the nest, and (2) determine if vegetation composition influences fledgling survival. In Chapter 4, I review the major insights gleaned from the two previous chapters about avian ecology in urban 
parks, and discuss conservation implications, potential management strategies, and directions for future study. 


\section{CHAPTER 2: Postfledging survival of Spotted Towhees (Pipilo maculatus) near urban park edges: evidence for an ecological trap}

\section{INTRODUCTION}

Gates and Gysel (1978) were among the first to use the term "ecological trap" to refer to a situation in which animals seemingly preferred to use low quality habitat. Robertson and Hutto (2006) went on to describe two types of traps: the "equalpreference" and "severe trap". In the former, animals do not show a preference for available habitats and settle in all with equal probability despite the fact that at least some are of lower quality. In that individuals do not exercise choice, Pattern and Kelly (2010) argued that the term "trap" should not be applied to the situation that Robertson and Hutto (2006) described. True traps exist because animals differentiate among habitats and choose the ones where survival and/or reproductive success are low (Pattern and Kelly 2010). Three mechanisms can lead to the existence of ecological traps: (1) settlement cues are altered such that a habitat increases in its attractiveness, but suitability does not change; (2) attractiveness of a habitat is unchanged but quality decreases; or (3) habitat attractiveness increases and quality decreases simultaneously (Robertson and Hutto 2006).

Examples of severe traps abound in the literature. For instance, Manatees (Trichechus manatus) gather in waters artificially heated by power plant effluent only to die when the effluent is turned off and temperatures drop (Packard et al. 1989). Adult dragonflies that are attracted to crude oil die when they land on it (Horváth et al. 1988). More commonly, poor choices over nest sites create ecological traps. Ries and Fagan (2003) showed that the Arizona Mantis (Stagmomantis limbata) placed most egg cases in 
edge habitat where bird predation on them was greatest, while mayflies find asphalt more attractive as oviposition sites than water (Kriska et al. 1998). Snapping Turtle (Chelydra serpentina) use of cold nest sites near residential buildings, while not causing death, results in biased offspring sex ratios (Kolbe and Janzen 2002).

Although clearly not taxon specific, most studies of ecological traps are of nesting birds, and their use of anthropogenically altered habitats. Expansive hayfields (Bollinger et al. 1990) or grass fields near airports (Kershner and Bollinger 1996) often attract high densities of breeding grassland birds that then experience nest failure when the fields are mowed. Birds sometimes also appear to prefer to place nests in exotic vegetation which, in some instances, leads to greater probability of nest predation (Remes 2003), even if only for a portion of the nesting season (Rodewald et al. 2010). Pattern and Kelly's (2010) position aside, Chestnut-collared Longspurs (Calcarius ornatus) provide an example of Robertson and Hutto's (2006) equal-preference trap: the birds showed equal use of habitats dominated by either exotic or native grasses despite the fact that nestling growth rates and nest success were lower in the former (Lloyd and Martin 2005).

However, the ecological trap most often cited as affecting birds is that of habitat edge, created as a consequence of habitat fragmentation arising usually from either agriculture (Johnson and Temple 1990) or timber harvest (Flaspohler et al. 2001). Gates and Gysel (1978), Chasko and Gates (1982), Johnson and Temple (1990), Flaspohler et al. (2001), and Weldon and Haddad (2005) all found that birds preferred to nest near edges (based on age-class distribution of breeding adults, site fidelity, or nest density or abundance), but that nest success or number of young fledged was lowest near edges. The cause of the low nest success across all studies was elevated rates of nest predation, 
which occurs because some nest predators are apparently more abundant in edge habitats as first suggested by Gates and Gysel (1978). While mammalian predators appear equally abundant in edge and interior habitats (Heske 1995, Chalfoun et al. 2002), snakes (Blouin-Demers and Weatherhead 2001, Chalfoun et al. 2002), Brown-headed Cowbirds (Molothrus ater; Howell et al. 2007), and corvids (Andrén 1992, Niemuth and Boyce 1997, Marzluff et al. 2004) all appear to show preferences for forest edges.

An important caveat to the study of ecological traps, noted by Robertson and Hutto (2006), is that changes in habitat or settlement cues that reduce fitness at one stage in the life cycle may not necessarily be present or relevant at another stage. For example, a trap that exists for a species at the egg stage may equally affect, not affect, or more strongly affect individuals as adults. Rarely, if ever, has this caveat been acknowledged, and all studies of ecological traps referenced above examined only one life history stage. For birds, this was universally the nesting stage. Most studies of avian reproductive success conclude at the end of the nestling phase, but in recent years researchers have begun to follow and study birds during the postfledging period (e.g. Anders et al. 1997, Yackel Adams et al. 2001, Moore et al. 2010, Balogh et al. 2011). To date, none of these efforts have been conducted within the framework of ecological traps.

The Spotted Towhee (hereafter towhee; Pipilo maculatus) is a resident groundnesting and ground-foraging inhabitant of early successional forests of the Pacific Northwest (Greenlaw 1996). Towhees are also common in urban parks and greenspaces in urban areas where they use multiple habitat types (Whittaker and Marzluff 2009). Research in parks and greenspaces of Portland, Oregon have shown that towhees nest in natural areas as small as 1-ha, and that populations in some parks appear to be 
sufficiently productive to be self-sustaining (S. Bartos Smith, unpubl. data). Towhee use of parks of all sizes exposes them to both edge and interior habitats, and contrary to expectations, Bartos Smith et al. (2011) showed that (1) the earliest breeding female towhees nested near edges and trails, (2) nests near park edges fledged significantly more young than nests in the interior of parks, and nests near park edges (3) produced heavier young, and (4) were less likely to incur partial brood losses. These data are all consistent with the suggestion that food is more abundant near edges than in the habitat interior. Assuming that predators are more common along edges (see above), Bartos Smith et al.'s (2011) results suggest that food availability overrides possible negative influences of predators on decisions about where to nest. Nonetheless, towhees appear to be sensitive to habitat fragmentation (Patten and Bolger 2003), and it is possible that higher nesting success near edges is offset by reduced survival of fledglings. Although Whittaker and Marzluff (2009) did not find that fledgling/juvenile towhee survival varied among habitats in Seattle, Washington, their study was not designed to investigate survival at the finer scale of habitat edge versus interior.

I conducted a two-year study of the reproductive ecology of Spotted Towhees at a residential park in the Portland, Oregon metropolitan region. My goals were to corroborate Bartos Smith et al.'s (2011) findings that nest success and productivity increased with proximity to edge, and to measure reproductive success in the postfledging period to evaluate whether fledgling survival varied in relation to use of habitat edges. More specifically, did survival during the postfledging period mirror patterns from earlier in the nest cycle, or was the trend of higher productivity near edges reversed such that edges ultimately functioned as ecological traps? To that end, I (1) 
measured fledgling production and nestling mass in relation to a nest's distance to a park edge or trail, (2) determined whether fledglings exhibited equal use of edge and interior habitats, and (3) documented survival of towhee fledglings in the immediate 30day period of postfledging parental care in relation to distance to park edge or trail.

\section{MeTHODS}

Study site.- Springbrook Park is a 24-ha urban park located near the border between Lake Oswego and Portland, Oregon, and is one of the four parks included in Bartos Smith et al.'s (2011) study. The park is bordered on the north side by a four-lane highway, on the east side by an athletic field, and on the west and south sides by residential backyards. The park has a network of heavily used recreational trails, including two major gravel trails that are $\sim 2 \mathrm{~m}$ wide, and several smaller mulch-covered trails that are $\sim 1 \mathrm{~m}$ wide (Fig. 2.1). Joggers, cross-country teams, and dog-walkers frequent the trails. Approximately $80 \%$ of dogs observed in the park are not leashed (A. A. Shipley, pers. observ.). The dominant tree species are Bigleaf Maple (Acer macrophyllum), Paper Birch (Betula papyrifera), and Red Alder (Alnus rubra). The welldeveloped understory includes native Sword Fern (Polystichum munitum), Salal (Gaultheria shallon), Indian-Plum (Oemleria cerasiformis), Dull Oregon-Grape (Mahonia nervosa), Beaked Hazelnut (Corylus cornuta), and Thimbleberry (Rubus parviflorus), as well as non-native Himalayan Blackberry (Rubus armeniacus), English Ivy (Hedera helix), and English Holly (Ilex aquifolium). Because the towhee population in Springbrook Park has been continuously monitored since 2004 (Bartos Smith et al. 2011), many of the adults in the park already had a unique combination of color bands 
when I began the study in 2008. In any given year, 25 to 30 towhee pairs defend territories.

Nest location and transmitter attachment.- I attempted to locate all nests in the park in 2008 and 2009. Towhees will attempt to raise 2 to 3 broods year ${ }^{-1}$, which necessitated near daily searches throughout the park beginning in late March and continuing through August. To facilitate nest finding and ensure complete coverage, I captured and marked as many unmarked adult towhees as possible. Males were captured using a recording of a towhee song played near a taxidermic mount that was set near a mist-net in the male's territory. Adult females were captured by playing a recording of a fledgling towhee distress call near a mist-net when the female had young that were $\geq 7$ days old. After capture, adults were banded with an aluminum U.S. Fish and Wildlife Service leg band and a unique combination of three colored leg bands. I also took standard morphological measurements (mass, wing chord, tarsus length, and tail length), and determined age (second year [SY] or after second year [ASY]) based on the contrast between the primary and greater wing coverts (Pyle 1997). Mass was measured to the nearest gram using a spring scale, tarsus length was measured to the nearest $0.1 \mathrm{~mm}$ using dial calipers, while wing chord and tail length were measured with a wing rule to the nearest millimeter. Adults were released at the capture site.

I used female behavior to find nests during nest construction (e.g., carrying nesting material) and incubation (e.g., prolonged stationary behavior). Parental behavior (e.g., carrying food and defensive behavior) was used to find nests with hatched young. Locations of all nests were recorded using a Garmin 72 (Garmin Ltd.) global positioning unit that was generally accurate to $<10 \mathrm{~m}$. I checked and recorded nest contents every 
three days, and measured (body mass, tarsus length, and $8^{\text {th }}$ primary length) and banded young 7 days after hatching. Nests were checked daily after the nestlings were banded to determine age at fledging (usually day 10 or 11 post-hatch). Spotted Towhees fledge prematurely if nestlings are handled after day 8 (A. A. Shipley, pers. observ.), and preliminary study indicated that attaching transmitters to 7 to 8 day old nestlings often proved fatal. Therefore, to ensure that the young were large enough to carry radio transmitters to follow postfledging survival, I postponed transmitter attachment until fledglings were out of the nest for three days. I then captured 1 or 2 fledglings from each brood, recorded body mass and tarsus length, and attached a Holohil BD-2 radio transmitter with a figure-eight leg harness (Rappole and Tipton 1991). All transmitters and harnesses were $\leq 5 \%$ of fledgling body mass in accordance with recommendations (Cochran 1980). Fledglings moved relatively little during the first three days after fledging and I was able to capture them either by hand from a perch or with a butterfly net after chasing them over the ground for short distances. Even after delaying transmitter attachment until three days post-fledge, some fledglings still did not meet the minimum mass requirement and were released without a transmitter.

Radio-tracking and survival. - I used a three-element folding Yagi antenna and an FM100 receiver (Advanced Telemetry Systems) to locate all transmittered fledglings daily between 0700 and 1900 PST until they reached 30 days post-fledge. Fledglings remain with and are largely dependent on their parents for food and protection over this period (Greenlaw 1996, A. A. Shipley, pers. observ.). Tracking also concluded at 30 days post-fledging because the transmitter battery life was only $\sim 50$ days, and I had to recover transmitters for future use. The order in which I tracked fledglings during the day was 
random, and fledglings were approached only as close as necessary to determine location and identity. I also avoided pushing fledglings away from where they were found. After locating a bird, I marked the location with a flag and a handheld global positioning unit (Garmin 72, Garmin Ltd.). If the bird was found alive in a backyard or otherwise outside the park boundaries, I recorded the bird as "out of park". Recording GPS coordinates of these latter locations was often unfeasible because it would have placed me on private property. I located dead fledglings outside of the park by searching at sites where signal locations remained stationary for more than one day. I attempted to determine cause of death by examining transmitter location and condition. Predation was attributed to Western Screech-owls (Megascops kennicottii) or Cooper's Hawks (Accipiter cooperii) when the transmitter and/or fledgling remains were found associated with an active nest of either species. Predation was attributed to domestic cats when the transmitter and/or fledgling remains were found in a backyard with either a cat sitting nearby or with a homeowner testimonial that his or her cat had killed the bird. If there was no direct evidence of the predator species, I recorded the fledgling as killed by an unknown predator if there were fledgling towhee feathers, body parts, or a partial carcass with apparent bite marks found near the transmitter. Additionally, if no fledgling carcass or body part was near the transmitter, I recorded the fledgling as killed by an unknown predator if the transmitter was damaged and was found well outside of the parents' territory before the fledgling could have become independent. After fledglings reached 30 days out of the nest, I recaptured and removed transmitters from survivors by "herding" each one into a long line of mist-nets, or by occasionally capturing a bird at night using a mist-net. 
I projected the GPS coordinates of nests and daily fledgling locations onto a map created using ArcGIS 9.2 (ESRI). Random locations were generated in ArcGIS using the Create Random Points tool. Trail systems and the park perimeter were projected onto the map using data collected with a Trimble GPS unit (J. E. McKay, unpubl. data). I used the Near Tool in ArcMap to calculate the shortest distance from each nest, every fledgling location, and all random locations to the nearest park edge and nearest recreational trail.

\section{Statistical Analyses}

Nest success and postfledging survival. - I used a two-sample $t$-test to evaluate the null hypothesis that towhee nests and random locations were equidistant to park edges and trails. To test for an association between nest success ( $\geq 1$ young fledged) and proximity to edges and trails, I used Mayfield logistic regression to account for exposure time (Hazler 2004) and treated distance to park edge or trail, year, or the date the nest was found (seasonality) as predictors of nest success. I used linear regression to test for relationships between distance of nest to edge and (1) clutch size, (2) brood size, (3) average nestling mass and tarsus length, and (4) number of fledglings produced per nest. The average nestling mass and size (tarsus and $8^{\text {th }}$ primary lengths) for each nest were used for statistical analyses. For each fledgling, all distances to edge and to trails were averaged over the 27 -day observation period (day 4 to 30 post-fledging) so that I had one estimate for each distance variable. I again used two-sample $t$-tests as described above to determine if fledgling locations were closer to edges or trails than were random locations, and to determine if fledgling survival was related to their average distance to edge or trail. Statistics are reported as means $\pm \mathrm{SE}$. 
To further explore the possibility of an effect of proximity to edges or trails on postfledging survival, I used Cox proportional hazards regressions (Cox 1972, Whittaker and Marzluff 2009) to estimate the cumulative survival probability. Cox models are well suited to studies in which individuals are relocated every day and the probability of detection is 1.0 (Manolis et al. 2002, Berkeley et al. 2007, Kaiser and Lindell 2007, Whittaker and Marzluff 2009). I ran three separate Cox proportional hazards regressions, and included either distance to edge or distance to trail, in addition to year, brood size, fledge date, body mass at banding, and the proportion of days the birds were found inside the park as covariates. In the first model, distance to edge was included as a categorical variable with two categories: above and below the median value of fledgling distance to edge $(31 \mathrm{~m})$. In the second model, three distance to edge categories were used: below the first quartile $(\leq 20 \mathrm{~m})$, the middle $50 \%(21-41 \mathrm{~m})$, and above the third quartile $(>41 \mathrm{~m})$. In the third model, distance to trail was included as a categorical variable, and fledglings that had average distance to trail values above and below the median $(26.8 \mathrm{~m})$ were grouped separately. For each of the three regressions, year, brood size, fledge date, body mass at banding, and the proportion of days the birds were found inside the park were entered into the model in the first step, and either distance to edge or distance to trail was entered into the model in the second step in order to determine if the distance variable had a significant effect on the survival model. Final models only included variables that were significant $(P \leq 0.05)$.

One of my goals was to determine survival rate over the first 30 days young were out of the nest. Therefore to account for the fact that fledgling survival was not known for the first three days out of the nest because the young were not tracked during this period, 
I used the daily survival rate of fledglings during days 4-7 post-fledge to estimate survival over the first three days to calculate an adjusted survival rate for the entire 30day postfledging period.

\section{RESULTS}

Nesting productivity. - I located 73 Spotted Towhee nests in Springbrook Park during $2008(\mathrm{~N}=27)$ and $2009(\mathrm{~N}=46)$. Fourteen nests in 2008 and 31 nests in 2009 were successful (Fig. 2.1). Daily survival rates calculated using the Mayfield logistic exposure model were 0.9582 (2008) and 0.9680 (2009). Assuming a 27-day period of nest occupancy (egg 1 to fledging), nest success was $31.6 \%(95 \% \mathrm{CI}=12.1 \%$ to $53.0 \%)$ in 2008 and $41.6 \%(95 \% \mathrm{CI}=22.3 \%$ to $59.7 \%)$ in 2009 . Combining years, an average of $37.5 \%$ of nests fledged young $(95 \% \mathrm{CI}=23.1 \%$ to $51.7 \%)$.

Nests were equidistant from park edges in $2008(41.3 \pm 5.38 \mathrm{~m})$ and 2009 (38.9 \pm $4.06 \mathrm{~m} ; t=0.357, \mathrm{df}=71, P=0.722)$ and therefore I pooled years for statistical analyses. Nests were significantly closer to park edges $(39.8 \pm 3.22 \mathrm{~m})$ than were random locations $(54.1 \pm 3.14 \mathrm{~m} ; t=-3.140, \mathrm{df}=166, P=0.002)$. Nests from $2008(17.1 \pm 2.99 \mathrm{~m})$ were significantly closer to recreational trails than were 2009 nests $\left(28.5 \pm 3.45 \mathrm{~m}\right.$; $t_{\text {unequal }}$ variance $=2.483, \mathrm{df}=69.81, P=0.015)$ and therefore I analyzed distance of nests to trails separately for the two years. The 2008 nests were significantly closer to trails $(17.1 \pm$ $2.99 \mathrm{~m})$ than were random locations $\left(32.1 \pm 2.83 \mathrm{~m}\right.$; $t_{\text {unequal variance }}=-3.649, \mathrm{df}=76.34, P$ $<0.001$ ), but in 2009 there was no difference in the distance between trails and either nests $(28.5 \pm 3.45 \mathrm{~m})$ or random locations $(32.1 \pm 2.83 \mathrm{~m} ; t=-0.779, \mathrm{df}=139, P=$ 0.437). 
However, in neither case did distance to a break in the forest (edge or trail) influence nest success. Distance to park edge did not differ between successful (37.6 \pm $3.78 \mathrm{~m})$ and failed nests $(43.3 \pm 5.83 \mathrm{~m} ; t=0.85, \mathrm{df}=71, P=0.397)$, and successful nests (2008: $20.5 \pm 4.59 \mathrm{~m} ; 2009: 26.7 \pm 4.18 \mathrm{~m})$ were no closer to trails than failed nests $(2008: 13.5 \pm 3.68 \mathrm{~m} ; t=-1.184, \mathrm{df}=25, P=0.248 ; 2009: 32.2 \pm 6.21 \mathrm{~m} ; t=0.744, \mathrm{df}=$ $44, P=0.461)$. Further analysis by logistic regression that accounted for exposure days showed that nest success was unrelated to year (coefficient $[\beta]=-0.265 \pm 0.414, P=$ $0.522)$, distance to edge $(\beta=0.003 \pm 0.008, P=0.683)$, or distance to trail $(\beta=-0.003 \pm$ $0.011, P=0.765)$, but that nests found earlier in the year were more likely to be successful $(\beta=0.021 \pm 0.009, P=0.015)$.

Results of linear regression analyses indicated that neither clutch size $(\beta=0.031, t$ $=0.216, \mathrm{df}=51, P=0.830)$ nor brood size $(\beta=-0.096, t=-0.647, \mathrm{df}=46, P=0.521)$ varied with distance to edge. On the other hand, I found that the number of fledglings produced from each nest, excluding complete nest failures, was greater from nests located near park edges $(\beta=-0.360 ; t=-2.530, \mathrm{df}=44, P=0.015$; Fig. 2.2). Moreover, nestlings were also heavier $(\beta=-0.342, t=-2.600, \mathrm{df}=52, P=0.012$; Fig. 2.3) and had longer $\operatorname{tarsi}(\beta=-0.285, t=-2.127, \mathrm{df}=52, P=0.038)$ when raised in nests located near park edges. Hence, young in nests closer to the park center were lighter, smaller, and more likely to die than were young located close to the park edge. Clutch size $(\beta=-0.007, t=-$ $0.047, \mathrm{df}=51, P=0.963)$, brood size $(\beta=0.055, t=0.373, \mathrm{df}=46, P=0.711)$, nestling mass $(\beta=0.114, t=0.818, \mathrm{df}=52, P=0.417)$, nestling tarsus $(\beta=0.082, t=0.590, \mathrm{df}=$ 
$52, P=0.558)$ and number of young fledged $(\beta=-0.018, t=-0.115, \mathrm{df}=44, P=$ 0.909) did not vary with distance to trail.

Fledgling survival and causes of mortality. - I radio-tracked 52 fledglings from 35 broods until either their death or the end of the 30-day postfledging period (Fig. 2.4). Seventeen broods had two transmittered fledglings each, and 18 broods had one transmittered fledgling each. Thirty-six fledglings (69.2\%) survived the actual 27-day tracking period (i.e., days 4 to 30 ; daily survival rate, $S,=0.986$ ). Of the 16 deaths, 7 occurred during days 4 to 7 out of the nest, 3 during the second week, 4 during the third week, and 2 during the fourth week (Table 2.1). After applying the daily fledgling survival rate for days 4 to $7(S=0.964)$ to the first 3 days out of the nest, I estimated it was likely that $3.7(\sim 4)$ fledglings would have died had I begun my tracking from the point of fledging, which is probably a conservative estimate. This resulted in an adjusted 30-day survival rate of $62.1 \%$. Two of 13 and 2 of 23 transmittered fledglings that survived the 27-day observation period from 2008 and 2009, respectively, were observed on the study site in the next year.

Predation was the cause of all 16 fledgling deaths (Table 2.1). Age at death (number of days post-fledge) did not differ among fledglings killed by domestic cats $(17.0 \pm 4.14$ days, $\mathrm{N}=4)$, raptors $(11.8 \pm 3.17$ days, $\mathrm{N}=6)$, or unidentified predators $(7.0$ \pm 2.30 days, $\mathrm{N}=6 ; F=2.37 \mathrm{df}=2, P=0.132$ ). In the case of fledglings killed by cats, fledgling carcasses with transmitters or transmitters surrounded by feathers (often with a bloodied harness) were found in residential backyards, either within a few meters of a cat, or the homeowner indicated that his or her cat had killed the fledgling. Based on the locations of these carcasses in different backyards, and assuming a cat would not leave 
the carcass of a fledgling it had killed in the territory (i.e., backyard) of another cat, 3-4 cats were responsible for these four fledgling deaths. Two towhee fledglings killed by cats were found in the same backyard, along with the carcasses of four birds of other species, both adults and fledglings. Three cats lived at this residence. Transmitters of 4 of 5 fledglings killed by Western Screech-owls (1 in 2008 and 4 in 2009) were found inside active screech-owl nest cavities. Two of the 2009 fledglings, from the same brood, were found in the same owl nest cavity. The third 2009 fledgling carcass was cached next to the base of a tree near the nest in which the first two young were found. Later observation of footage from an infrared, motion-activated camera at the site showed that a screechowl retrieved the carcass. The fourth 2009 fledgling killed by an owl was found in a different active screech-owl nest box. I also found a transmitter near the base of a tree with an active Cooper's Hawk nest. Five of six fledglings killed by unidentified predators died between days 4 and 7. In four of these six cases, the transmitter was found next to fledgling towhee feathers, body parts, or a partial carcass with bite marks. In two of the six cases, a damaged transmitter with a bloodied harness was found without a carcass, but it was well outside the parents' territory before the fledgling could have become independent. Two of the six fledglings killed by unknown predators were likely killed by cats. The remains of these two fledglings were found in the same homeowner's driveway, one in each year. Predators other than cats would have been unlikely to have deposited the carcasses in the same driveway, but because there was no direct evidence that cats were responsible, I conservatively grouped them with unidentified predators for analyses.

Distance to edge did not differ between fledglings tracked during 2008 (38.0 \pm $4.14 \mathrm{~m}, \mathrm{~N}=13)$ and $2009(32.2 \pm 2.89 \mathrm{~m}, \mathrm{~N}=41 ; t=1.014, \mathrm{df}=52, P=0.315)$, so 
fledglings from both years were pooled for my analyses of survival in relation to distance to edge. Average fledgling locations were significantly closer to park edges $(33.6 \pm 2.42 \mathrm{~m})$ than random locations $\left(54.1 \pm 3.14 \mathrm{~m} ; t_{\text {unequal variance }}=-5.17, \mathrm{df}=146.9\right.$, $P<0.001$ ). In addition, average locations of fledglings that died during the 27 -day tracking period were significantly closer to park edges $(23.5 \pm 2.80 \mathrm{~m})$ than for fledglings that survived the 27-day tracking period $(37.8 \pm 3.02 \mathrm{~m} ; t=-2.89, \mathrm{df}=50, P=0.006)$. Average distance to edge did not differ among fledglings killed by cats $(27.6 \pm 3.89 \mathrm{~m})$, raptors $(21.3 \pm 4.70 \mathrm{~m})$, or unidentified predators $(23.0 \pm 5.61 \mathrm{~m} ; F=0.360, \mathrm{df}=2, P=$ 0.704). When fledglings that were killed by cats were removed from the analysis, locations of fledglings that were killed by raptors and unidentified predators were still significantly closer to park edges $(22.2 \pm 3.50 \mathrm{~m}, \mathrm{~N}=12)$ than locations of survivors $(37.8 \pm 3.02 \mathrm{~m}, \mathrm{~N}=36 ; t=-2.771, \mathrm{df}=46, P=0.008)$.

Distance between fledglings and the nearest recreational trail did not differ between $2008(23.2 \pm 3.01 \mathrm{~m})$ and $2009(28.53 \pm 1.85 \mathrm{~m} ; t=-1.444, \mathrm{df}=52, P=0.155)$, and thus data were pooled for distance to trail analyses. Average fledgling locations were no closer to park trails $(27.2 \pm 1.60 \mathrm{~m})$ than random locations $\left(27.6 \pm 2.83 ; t_{\text {unequal }}\right.$ variance $=$ $-1.51, \mathrm{df}=138.7, P=0.134)$. Towhee fledglings that died $(25.1 \pm 3.11 \mathrm{~m})$ or survived $(27.6 \pm 1.90 \mathrm{~m}$; $)$ were also equidistant from trails $(t=-0.71, \mathrm{df}=50, P=0.479)$.

In the first Cox proportional hazards regression, the overall model was not significant when year, brood size, fledge date, mass at banding, and proportion of time spent in the park were entered (Cox proportional hazards $\chi^{2}=8.176, \mathrm{df}=5, P=0.147$ ). However, when distance to edge was also entered into the model as two distance 
categories (below [near] and above [far] median distance to edge) in the second block, the omnibus test for the overall model became significant (Cox proportional hazards $\chi^{2}=$ $25.808, \mathrm{df}=6, P<0.001)$. Including distance to edge had a significant effect on the model (change in Cox proportional hazards $\chi^{2}=13.230, \mathrm{df}=1, P<0.001$ ). In this model, fledglings farther away from the edge were more likely to survive $(\exp [\mathrm{B}]=11.71, P=$ 0.001; Fig. 2.5), as were fledglings that spent more time in the park $(\exp [\mathrm{B}]=0.96, P=$ $0.009)$ and fledged earlier in the year $(\exp [\mathrm{B}]=0.97, P=0.026)$. When only the significant variables were included in the model (time spent in park, fledge date, and distance to edge), the overall Cox proportional hazards $\chi^{2}$ was $23.494(P<0.001)$.

The entry of distance to edge as a three category variable (near [first quartile], intermediate [middle 50\%], and far [fourth quartile]) in the second Cox proportional hazards regression in the second block also had a significant effect on the model (change in Cox proportional hazards $\chi^{2}=12.335, \mathrm{df}=2, P=0.002$ ), and the omnibus test for the overall model became significant (Cox proportional hazards $\chi^{2}=18.238, \mathrm{df}=7, P=$ 0.011; Fig 2.6). As before, fledglings that spent more time in the park $(\exp [\mathrm{B}]=0.96, P=$ $0.038)$ and fledged earlier in the year $(\exp [\mathrm{B}]=0.97, P=0.019)$ were significantly more likely to survive. Survival did not differ between years, or vary with brood size or mass at banding. When only significant variables were included in the model (time spent in park, fledge date, and distance to edge), the overall Cox proportional hazards $\chi^{2}$ was 17.136 ( $P$ $=0.002)$

In the third Cox proportional hazards regression, entering distance to trail in the second step had no effect on the model (change in Cox proportional hazards $\chi^{2}=0.219$, $\mathrm{df}=1, P=0.640)$ and the omnibus test for the overall model remained insignificant (Cox 
proportional hazards $\left.\chi^{2}=8.301, \mathrm{df}=6, P=0.217\right)$. Thus, cumulative survival functions did not differ between distance to trail categories $(\exp [\mathrm{B}]=1.316, P=0.641$; Fig 2.7). Although survival was still significantly negatively related to fledge date $(\exp [\mathrm{B}]=0.97, P=0.034)$, survival was not significantly related to distance to trail, time spent in park, year, brood size, or mass at banding. Simultaneous incorporation of distance to trail and distance to edge, along with fledge date and time spent in the park resulted in a significant effect of the latter three variables (Cox proportional hazards $\chi^{2}=$ 24.426, $\mathrm{df}=4, P<0.001$; distance to edge: $\exp [\mathrm{B}]=10.453, P<0.001$; fledge date: $\exp [\mathrm{B}]=0.976, P=0.057$; time spent in the park: $\exp [\mathrm{B}]=0.960, P=0.020$ ) but with no effect of distance to trail on fledgling survival $(\exp [\mathrm{B}]=1.351, P=0.574)$.

\section{DiscusSiON}

Nesting productivity. - Nest success was moderate and did not differ between years, with nearly $40 \%$ of nests fledging young. Furthermore, my results showed a striking correspondence with Bartos Smith et al. (2011) in that the likelihood of total nest failure did not vary with distance from the edge of the park or distance to the nearest trail, but that among successful nests, the number of young to fledge increased as nests were positioned closer to the edge of the park. Given that neither clutch size nor brood size varied with distance to edge, partial brood loss during the nestling period was higher in nests from the park interior. That this was due mainly to starvation is suggested strongly by the fact that nestlings from edge nests were both heavier and larger (i.e., longer tarsi) than nestlings from interior nests, in addition to there being more young to fledge from successful nests near the edge. 
My study's replication of Bartos Smith et al.'s (2011) finding of the absence of an edge effect in Portland parks and greenspaces, i.e., an increased probability of nest failure near edges (Gates and Gysel 1978, Flaspohler et al. 2001, Manolis et al. 2002), suggests that edges are not inherently poor habitat. To the contrary, edges have often been suggested to be attractive to birds because of enhanced food resources (e.g., Gates and Gysel 1978), and our results on nesting productivity and nestling size are consistent with this view. The relatively high nest success, which was unaffected by distance to edge, suggests that nest predator activity was spread evenly throughout the park. Studies conducted elsewhere suggest that the abundance of small to medium sized mammals varies little with distance from habitat edges in fragmented forest landscapes (Heske 1995, Chalfoun et al. 2002). On the other hand, brood parasitic Brown-headed Cowbirds (Howell et al. 2007), corvid nest predators (Andrén 1992, Niemuth and Boyce 1997, Marzluff et al. 2004), and especially snakes (Blouin-Demers and Weatherhead 2001, Chalfoun et al. 2002) show high activity along edges. Cowbirds are not abundant in Portland's parks and greenspaces (M. T. Murphy, unpubl. data) and not a single Springbrook towhee nest was parasitized in 2008 or 2009. Snake diversity is low in northwest Oregon (Nussbaum et al. 1983, St. John 2002), and I rarely saw snakes in the parks and greenspaces. Snakes are often cited as the primary cause of nest loss in many studies, and their virtual absence from my study site (and others in the urban landscape) may explain why neither Bartos Smith et al. (2011) nor I detected an increased probability of nest failure along habitat edges.

Fledgling survival and causes of mortality.- Just over $60 \%$ of Spotted Towhees survived the 30-day period that followed their departure from the nest. Domestic cats and 
Western Screech-owls were major predators of fledglings, and a fledgling's proximity to the park edge was an important predictor of its survival. Whittaker and Marzluff (2009) also reported that predators were the sole source of fledgling Spotted Towhee mortality in urban Seattle, Washington, but their estimate of postfledging survival for fledglings still dependent on their parents was higher $(83.5 \%$ when adjusted to a 30 -day observation period). This relatively large difference in survival rates may be due to an apparent absence of predation by domestic cats on young towhees at the Seattle study sites (K. Whittaker, pers. comm.), or because of a small sample size of fledgling towhees in Whittaker and Marzluff's study (15 individuals where the birds' fates were known with certainty). Other recent estimates of fledgling survival during the postfledging dependent period obtained through the use of radio telemetry vary considerably among species and habitats (Table 2.2), but fledgling survival of a range of species that nest in mature forests averaged $57.3 \%$, versus $61 \%$ in grasslands and $65.4 \%$ in urban areas.

Predation appeared to be the only cause of death among fledgling Spotted Towhees in Springbrook Park (Table 2.1). Other fledgling telemetry studies in mature forests and grasslands have confirmed predators as the nearly exclusive cause of death. Many native predators kill fledgling birds (see Table 2.2). Domestic cats are known to be predators of nestlings (Haskell et al. 2001) and of fledgling and juvenile birds in urban areas (Balogh et al. 2011). Baker et al. (2005) surveyed urban cat owners about the prey items that their cats brought home, and found that cat predation on birds was highest in the spring and summer, which probably reflected predation of fledgling and juvenile birds. Cats were important predators of fledgling Spotted Towhees in Springbrook Park, causing 4 of 10 deaths when the predators were known with high certainty, and probably 
at least 6 of all 16 deaths. I regularly observed cats on the park's edges, near residential backyards, and on remote cameras day and night. Crooks and Soulé (1999) showed that cat abundance exhibited a strong negative relationship with coyote abundance, suggesting that coyotes killed cats. I observed coyotes in Springbrook Park on several occasions and cat carcasses were occasionally found in the park. Presumably, in the absence of coyotes, cats may have had an even greater effect on fledgling Spotted Towhees survival in Springbrook Park.

Native raptors, especially Western Screech-owls, also had an important effect on fledgling Spotted Towhee survival. VanCamp and Henny (1975) found that the proportion of birds in the diet of Eastern Screech-owls (Megascops asio) increased from $30 \%$ in fall and winter to $68 \%$ in the nesting season. My data suggest that three transmittered towhee fledglings (two from the same brood) in 2009 were killed by the same pair of owls within a two-day period. A fourth fledgling was killed by another pair of owls. Thus, screech-owls may commonly prey upon fledgling birds, particularly when they are hunting to feed their own young, but their effects are likely to be limited and localized because of territorial spacing of screech-owls. Domestic cats are not limited by such territorial behavior, and in urban parks large enough to support screech-owls and other raptors, the predation pressure on fledgling birds by domestic cats near park edges may be additive to the effects of native predators and thus be highly detrimental to bird populations.

Fledgling condition.- Nestling or fledgling condition, as measured by body mass or tarsus length, has been shown in several studies to predict fledgling survival during the postfledging dependent period (Naef-Daenzer et al. 2001, Ringsby et al. 1998, Suedkamp 
Wells et al. 2007). However, most studies, including the present one, have found that nestling body mass or condition did not predict survival (Sullivan 1989, Anders et al. 1997, Berkeley et al. 2007, Brown and Roth 2004). Certainly, the size or condition of nestlings may be an important predictor of survival when poor weather is an important source of mortality (Suedkamp Wells et al. 2007) because fledgling survival may be threatened during periods of inclement weather or shortages of food. Sullivan (1989) found, for instance, that heavy juvenile Yellow-eyed Juncos (Junco phaenotus) were less likely to die during the first few weeks of independence. However, when young remain under parental care, it appears that predators are the leading cause of death in most studies for which data exist (Balogh et al. 2011, King et al. 2006, Moore et al. 2010, Naef-Daenzer et al. 2001).

Edges and trails. - Spotted Towhees at Springbrook Park nested closer to both park edges and recreational trails than expected by chance. However, despite an apparent attraction to edges, towhees did not seemingly benefit by nesting close to edges because, as Bartos Smith et al. (2011) also found, the failure or success of entire nests at Springbrook Park was unrelated to distance to either edges or trails. However, defining success on the basis of whether a nest fledged at least one nestling is rather coarse, and my more detailed analysis of productivity showed that the number of young to fledge from successful nests declined with increasing distance from the edge. Brood reduction might occur through partial predation of broods, but the fact that nestling body mass and overall size (i.e., tarsus length) also declined with increasing distance from the edge suggests that nestlings were fed less and were more likely to starve in nests located farther from the edge. Bartos Smith et al. (2011) found an identical pattern in their three- 
year study of Spotted Towhees in four urban parks in Portland, including Springbrook.

The consistency of Bartos Smith et al. (2011) and my results suggests that the attraction of towhees to park edges is likely related to enhanced food resources.

On the other hand, the probability that a fledging would die within the first month out of the nest increased with increasing proximity to the park edge regardless of whether 2 or 3 categories for distance of a fledgling to the park edge was used. In addition, young that fledged earlier in the season and spent little time outside of the park were also less likely to die, an effect that was independent of distance to edge. In fact, none of the 12 fledglings that were located the farthest from the park edge died during the 27-day observation period. Thus, paradoxically, despite the fact that both nests and fledglings were more likely to be found near edges and that young were heavier and more of them fledged when nests were near edges, the probability that fledglings would survive the postfledging period was lower for fledglings near edges. I suggest that the conflicting results arise from the fact that the cause of offspring death changes from a combination of food limitation and predation when young are in the nest to entirely predation as nestlings leave the nest and begin to move with their parents.

Other studies have failed to find an association between edge habitat and survival through comparisons of fledgling survival among different sized habitat fragments (Luck 2003, Rush and Stutchbury 2008, Moore et al. 2010). I focused instead on a single habitat patch to test for a relationship between proximity to habitat edge and fledgling survival, and my results show that fledglings were significantly more likely to die near edges than in the interior, and the only source of mortality was predation. It follows that there is likely an association between fledgling towhee predators and the edge. As noted above, 
cats were important predators of fledgling towhees, and the relationship between cats and the park edge is understandable, as at least half of the park is bordered by residential backyards. Crooks and Soulé (1999) found that the smallest habitat fragments had the greatest cat abundance, because smaller fragments have proportionally more edge that is accessible to domestic cats.

Nonetheless, distance to edge for fledglings killed by cats, raptors, and unknown predators did not differ, and therefore most predator activity appeared to be concentrated near habitat edges. It is not immediately clear why this is so, but one possibility is that ambient light from houses near the park edges enable screech-owls to hunt more efficiently during the night. Another possibility is that predators kill prey (i.e., towhee fledglings) close to the park edge because that is where prey are most densely grouped. Towhees nested closer to park edges than expected based on random placement, and towhee family groups tend to remain within the parent's territory during the postfledging period (A. A. Shipley, unpubl. data). This combined with the fact that predators during 2008 and 2009 also nested near edges probably put many fledgling towhees within the foraging territory of both raptor species.

Unlike their affiliation with park edge, fledgling towhees moved independently of trails and fledgling survival was unrelated to distance to a recreational trail. Sinclair et al. (2005) reported that mammalian nest predators may use wider trails as travel corridors (Sinclair et al. 2005), but this was an unlikely factor in the Springbrook system because the primary fledgling predators were raptors and cats, and the latter probably entered the park directly from yards that abutted the park edge. 
Urban parks: safe refuge or ecological trap? - Patterns revealed in Bartos

Smith et al.'s (2011) and my study suggest strongly that edges are seemingly attractive to female towhees. Edges receive abundant solar radiation that may enhance primary productivity and yield more natural food (Murcia 1995, Jokimäki et al. 1998). Additionally, anthropogenic sources of food (i.e., bird feeders) in the backyards that border the park may offer an easy food source. Indeed, adult towhees regularly use bird feeders during the nesting season (S. Bartos Smith and A. A. Shipley, pers. observ.), and either give this supplementary food directly to their nestlings and fledglings, or, more likely, eat the supplementary food themselves, allowing the adults more time to forage for their young. Birdfeeders in residential backyards may in fact serve as the cue that attracts towhees to settle and nest near park edges. Providing food during the winter may increase the number and density of resident birds that are attracted to the area and remain there to breed in the next season (Jansson et al. 1981). This provisioning of food may allow females to spend less time foraging and more time at the nest (Robb et al. 2008). Robb et al.'s (2008) review of the effects of feeders on bird populations found that when birds passed on supplementary food to their young, growth rates were positively affected in $56 \%$ of the studies, and that the young given supplementary food were more likely to fledge than non-supplemented young in $64 \%$ of the studies.

Towhees nesting near edges inevitably have fledglings that spend more time near edges, which I confirmed in the present study by determining that fledglings were more likely to be found near edges than near random locations. While towhee nest success was not affected by proximity to edges, fledgling towhees were more likely to die near the park's edges. Domestic cats, one of the fledgling towhees' main predators, are likely to 
have an important effect on bird populations, especially in parks or habitat fragments where coyotes are absent. The heavy use of edges for nesting by towhees and relatively high nest productivity of nests found there, is countered by higher fledgling mortality near edges. Indeed, edges may be acting as an ecological trap (sensu Gates and Gysel 1978), whereby animals are drawn to an apparently attractive habitat in which they ultimately fare poorly.

To determine whether high towhee fledgling mortality near edges is offset by greater fledgling production from nests near edges, I used a STELLA-based stochastic model of nest success and fledgling survival for 1,000 nests at each of the three distance to edge categories. For each nest, I determined if it produced any young by using a Monte Carlo simulation based upon the observed probability of nest success at the close $(\leq 21$ $\mathrm{m})$, medium (21.1 to $41 \mathrm{~m})$ and most distant ( $>41 \mathrm{~m})$ distance to edge categories. I obtained the number of young per successful nest by drawing randomly from a normal distribution that had the mean and standard deviation observed at the three distance categories. Finally, to determine if each fledgling that was produced survived to 30 days, I again used a Monte Carlo simulation based upon the observed probability of survival at the three distance categories. For the latter analysis, all fledglings were treated as independent events. This resulted in an estimate of the number of fledglings produced per nest for each distance to edge category that would have survived from egg-laying to 30 days post-fledging. As shown in Table 2.3, despite lower fledgling production per nest, areas farthest from the edge yielded the highest numbers of surviving fledglings per nest 30 days after fledging. It would thus seem most adaptive for towhees to nest in the park interior, yet they prefer to nest near edges. The resulting severe ecological trap (sensu 
Robertson and Hutto [2006]) that ensues arises from this apparent preference for the inferior habitat. Additionally, if towhees are indeed using birdfeeders as settlement cues, then I argue that the trap is occurring via Robertson and Hutto's (2006) third mechanism: the attractiveness of the habitat increases while the habitat quality simultaneously decreases.

To date, all avian studies of edges as ecological traps indicate that nest success or number of young fledged was lower near the edges of forests bordering rural fields, grasslands, corridors, or clearcuts (Gates and Gysel 1978, Chasko and Gates 1982, Johnson and Temple 1990, Flaspohler et al. 2001, Weldon and Haddad 2005). In contrast, I found that the number of young to fledge was higher near edges bordering residential backyards. On the basis of these results, one might assume that these types of edges are beneficial for towhees. Only after examining another life history stage, the postfledging period, was I able to determine that the increased production of fledglings near edges did not, in fact, compensate for the higher mortality of fledglings near edges. Thus, my results are consistent with the results of others in that edges can serve as ecological traps for birds, but my results show that the detrimental effects of an ecological trap may not manifest itself at the first life history stage.

While fledgling towhee survival in an urban park was relatively high, park edges were particularly dangerous places for fledglings. More research is needed to determine if this type of ecological trap exists for other urban bird species that use bird feeders, have vulnerable fledglings, and nest in areas with unregulated mesopredators, particularly domestic cats. While ecological traps have been reported across a range of bird, insect, mammal, and reptile species, almost none of these studies have examined more than one 
stage in the animal's life cycle. My results show that a habitat may appear beneficial to a species during one stage, but the habitat's suitability may be reversed during another life cycle stage while the habitat's attractiveness remains high. This has important implications for conservation, as phenomena such as ecological traps created by anthropogenic changes in the environment could be overlooked if only one life history stage is studied. 
TABLES AND FIGURES

TABLE 2.1. Numbers of Spotted Towhee fledglings killed by different predators during the first four weeks post-fledging in an urban park in Portland, Oregon, 2008-2009. Raptors include Cooper's Hawks and Western Screech-owls. Unknown predators could not be identified.

\begin{tabular}{lccccccccc}
\hline & \multicolumn{4}{c}{2008} & & \multicolumn{4}{c}{2009} \\
\cline { 2 - 4 } Predator & Week 1 & Week 2 & Week 3 & Week 4 & & Week 1 & Week 2 & Week 3 & Week 4 \\
\hline Cat & 0 & 0 & 0 & 0 & & 0 & 1 & 2 & 1 \\
Raptor & 1 & 0 & 0 & 0 & & 1 & 2 & 1 & 1 \\
Unknown & 1 & 0 & 1 & 0 & & 4 & 0 & 0 & 0 \\
\hline
\end{tabular}


TABLE 2.2. Survival rates and predators of birds during the first 30 days post-fledging in different habitats. Fledglings were tracked via radio transmitters except where indicated.

\begin{tabular}{|c|c|c|c|c|c|}
\hline Species & $\mathrm{N}$ & Habitat & $\begin{array}{l}\text { Survival } \\
\text { Rate } \%{ }^{a}\end{array}$ & Predators $^{b}$ & Reference \\
\hline $\begin{array}{l}\text { Wood Thrush } \\
\text { (Hylocichla } \\
\text { mustelina) }\end{array}$ & 45 & Mature forest & 63.5 & $\begin{array}{l}\text { Cooper's Hawk, } \\
\text { Timber Rattlesnake, } \\
\text { Broad-winged } \\
\text { Hawk }\end{array}$ & Anders et al. 1997 \\
\hline $\begin{array}{l}\text { Ovenbirds } \\
\text { (Seiurus aurocapilla) }\end{array}$ & 41 & Mature forest & 69.6 & $\begin{array}{l}\text { Eastern Chipmunk, } \\
\text { Accipiter spp. }\end{array}$ & King et al. 2006 \\
\hline $\begin{array}{l}\text { Great Tits } \\
\text { (Parus major) } \\
\text { and Coal Tits } \\
\text { (Parus ater) }\end{array}$ & 342 & Mature forest & 38.9 & $\begin{array}{l}\text { Eurasian Jay, } \\
\text { Great Spotted } \\
\text { Woodpecker, } \\
\text { Sparrowhawk, } \\
\text { Marten }\end{array}$ & $\begin{array}{l}\text { Naef-Daenzer et al. } \\
2001\end{array}$ \\
\hline $\begin{array}{l}\text { Western Bluebirds } \\
\text { (Sialia mexicana) }\end{array}$ & 26 & $\begin{array}{l}\text { Restoration- } \\
\text { treated forest }\end{array}$ & 51.2 & Unknown & Wightman 2009 \\
\hline $\begin{array}{l}\text { Dickcissels } \\
\text { (Spiza americana) }\end{array}$ & 60 & Grassland & 52.2 & Unknown & Berkeley et al. 2007 \\
\hline $\begin{array}{l}\text { Eastern Meadowlarks } \\
\text { (Sturnella magna) }\end{array}$ & 107 & Grassland & 83.5 & $\begin{array}{l}\text { Northern } \\
\text { Watersnake, } \\
\text { Bullsnake }\end{array}$ & $\begin{array}{l}\text { Suedkamp Wells et al. } \\
2007\end{array}$ \\
\hline $\begin{array}{l}\text { Eastern Meadowlarks } \\
\text { (Sturnella magna) }\end{array}$ & 50 & Grassland & $83.5-88.7$ & $\begin{array}{l}\text { Eastern Garter } \\
\text { Snake }\end{array}$ & Kershner et al. 2004 \\
\hline $\begin{array}{l}\text { Lark Buntings } \\
\text { (Calamospiza } \\
\text { melanocorys) }\end{array}$ & 23 & Grassland & 22.2 & Raptors & $\begin{array}{l}\text { Yackel Adams et al. } \\
2001\end{array}$ \\
\hline $\begin{array}{l}\text { White-throated } \\
\text { Robins } \\
\text { (Turdus assimilis) }\end{array}$ & 53 & $\begin{array}{l}\text { Coffee and } \\
\text { pasture }\end{array}$ & 56.2 & $\begin{array}{l}\text { Swallow-tailed Kite, } \\
\text { Snakes }\end{array}$ & $\begin{array}{l}\text { Cohen and Lindell } \\
2004\end{array}$ \\
\hline $\begin{array}{l}\text { Rose-breasted } \\
\text { Grosbeaks } \\
\text { (Pheucticus } \\
\text { ludovicianus) }\end{array}$ & 42 & $\begin{array}{l}\text { Forest fragments } \\
\text { surrounded by } \\
\text { agriculture }\end{array}$ & 49.8 & $\begin{array}{l}\text { Eastern Chipmunk, } \\
\text { Common Grackle, } \\
\text { Eastern Garter } \\
\text { Snake, Raptors }\end{array}$ & Moore et al. 2010 \\
\hline $\begin{array}{l}\text { Hooded Warblers } \\
{\text { (Wilsonia citrina })^{\mathrm{c}}}^{\mathrm{c}}\end{array}$ & 52 & $\begin{array}{l}\text { Forest fragments } \\
\text { surrounded by } \\
\text { agriculture }\end{array}$ & 16.7 & Unknown & $\begin{array}{l}\text { Rush and Stutchbury } \\
2008\end{array}$ \\
\hline $\begin{array}{l}\text { Spotted Towhees } \\
\text { (Pipilo maculatus) }\end{array}$ & 15 & Urban landscape & 83.5 & $\begin{array}{l}\text { Mammals } \\
\text { and Birds }\end{array}$ & $\begin{array}{l}\text { Whittaker and } \\
\text { Marzluff } 2009\end{array}$ \\
\hline $\begin{array}{l}\text { American Robins } \\
\text { (Turdus migratorius) }\end{array}$ & 15 & Urban landscape & 59.8 & $\begin{array}{l}\text { Mammals } \\
\text { and Birds }\end{array}$ & $\begin{array}{l}\text { Whittaker and } \\
\text { Marzluff } 2009\end{array}$ \\
\hline
\end{tabular}




\begin{tabular}{llll}
$\begin{array}{l}\text { Gray Catbirds } \\
\text { (Dumatella }\end{array}$ & $47 \quad$ Urban landscape & $52.9 \quad \begin{array}{l}\text { Domestic Cat, } \\
\text { Black Rat Snake, } \\
\text { carolinensis) }\end{array}$ & Ralogh et al. 2011 \\
& & Hawk \\
& & \\
\hline
\end{tabular}

${ }^{a}$ Survival rates were calculated by extrapolating the daily survival rate from the literature to 30 days postfledging to enable direct comparison between studies.

${ }^{\mathrm{b}}$ Cooper's Hawk (Accipiter cooperii), Timber Rattlesnake (Crotalus horridus), Broad-winged Hawk (Buteo platypterus), Eastern Chipmunk (Tamias striatus), Eurasian Jay (Garrulus glandarius), Great Spotted Woodpecker (Dendrocopos major), Sparrowhawk (Accipiter nisus), Marten (Martes sp.), Northern Watersnake (Nerodia sipedon), Bullsnake (Pituophis catenifer), Swallow-tailed Kite (Elanoides forficatus), Common Grackle (Quiscalus quiscula), Eastern Garter Snake (Thamnophis sirtalis), Domestic cat (Felis domesticus), Black Rat Snake (Pantherophis obsoletus), and Red-shouldered Hawk (Buteo lineatus)

${ }^{\mathrm{c}}$ The survival rate for Hooded Warbler fledglings was determined by following radio-tagged adult warblers. 
TABLE 2.3. The number of Spotted Towhee fledglings per nest alive 30 days post-fledging at varying distances to park edge based on the probability of nest success, the number of young fledged per successful nest, and postfledging survival rates in an urban park in Lake Oswego, Oregon, 2008-2009. Values are reported as means $\pm \mathrm{SE}$.

\begin{tabular}{cccccc}
\hline $\begin{array}{c}\text { Distance to } \\
\text { edge }(\mathrm{m})\end{array}$ & $\begin{array}{c}\text { Probability } \\
\text { of nest } \\
\text { success }\end{array}$ & $\begin{array}{c}\text { Mean \# of young } \\
\text { fledged per successful } \\
\text { nest }^{\mathrm{a}, \mathrm{b}}\end{array}$ & $\begin{array}{c}\text { Mean \# of young } \\
\text { fledged per nest }\end{array}$ & $\begin{array}{c}\text { Probability } \\
\text { of fledgling }_{\text {survival }}\end{array}$ & $\begin{array}{c}\text { Mean \# of young per } \\
\text { nest alive 30 days } \\
\text { post-fledging }^{\mathrm{a}}\end{array}$ \\
\hline$\leq 20$ & 0.424 & $2.62 \pm 0.239 \mathrm{~A}$ & $1.09 \pm 0.0457 \mathrm{~A}$ & 0.50 & $0.55 \pm 0.0283 \mathrm{C}$ \\
$21-41$ & 0.363 & $2.67 \pm 0.236 \mathrm{~A}$ & $1.02 \pm 0.0446 \mathrm{~A}$ & 0.64 & $0.67 \pm 0.0335 \mathrm{~B}$ \\
$>41$ & 0.351 & $2.15 \pm 0.209 \mathrm{~B}$ & $0.80 \pm 0.0376 \mathrm{~B}$ & 1.00 & $0.80 \pm 0.0376 \mathrm{~A}$ \\
\hline
\end{tabular}

${ }^{\mathrm{a}} \mathrm{A}, \mathrm{B}, \mathrm{C}$ coding indicates significant differences at the $\alpha=0.05$ level.

${ }^{\mathrm{b}}$ Sample sizes are 16, 9, and 20 for number of young per successful nest for nests $\leq 21 \mathrm{~m}, 21-41 \mathrm{~m}$, and > $41 \mathrm{~m}$ from edge, respectively. 


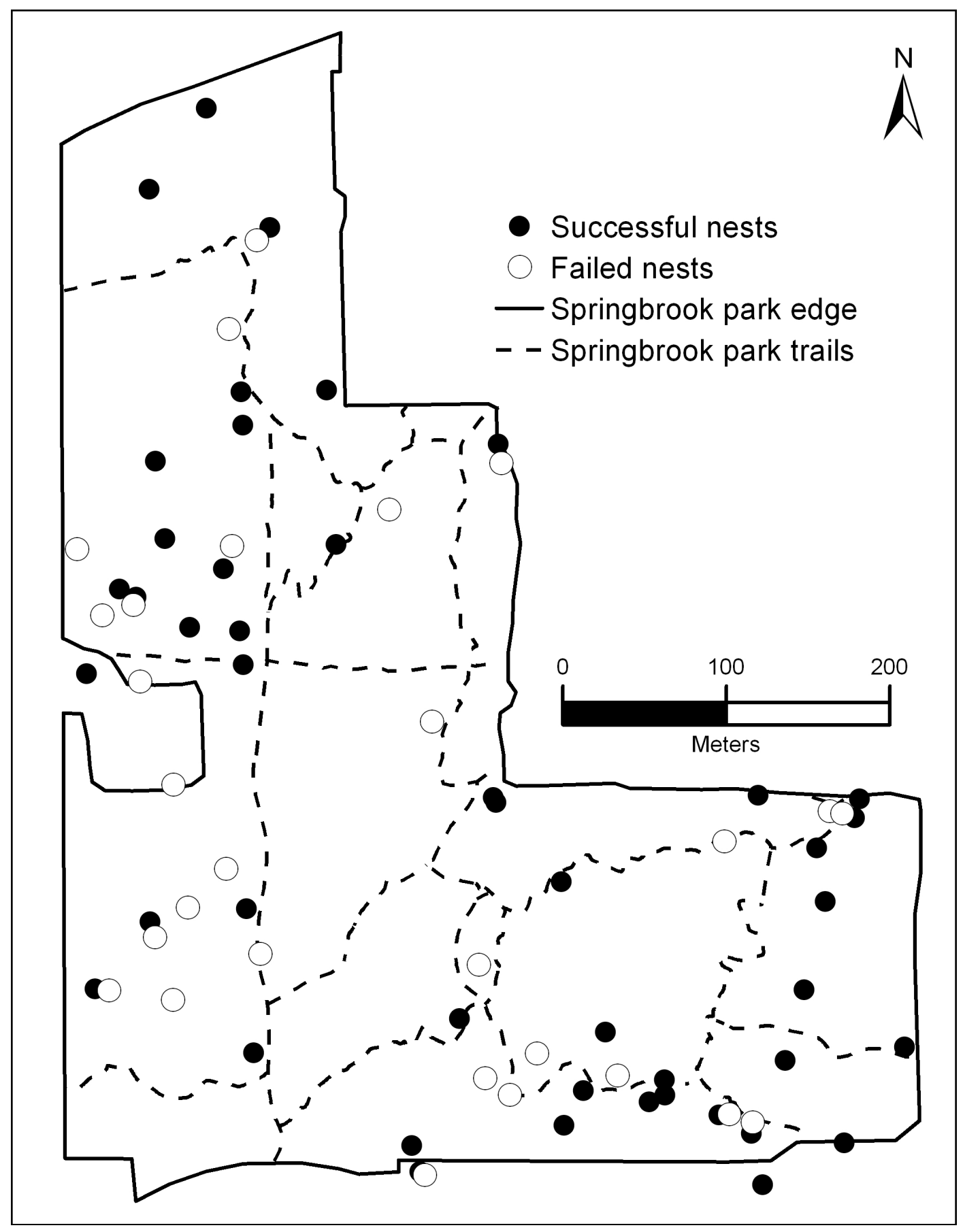

FIg. 2.1. Successful $(N=45)$ and failed $(N=28)$ Spotted Towhee nests from 2008 and 2009 in Springbrook Park, an urban park located in Lake Oswego, Oregon. Vegetation extends slightly beyond the park's official boundaries and therefore some pairs also placed nests outside the park's official edge. 


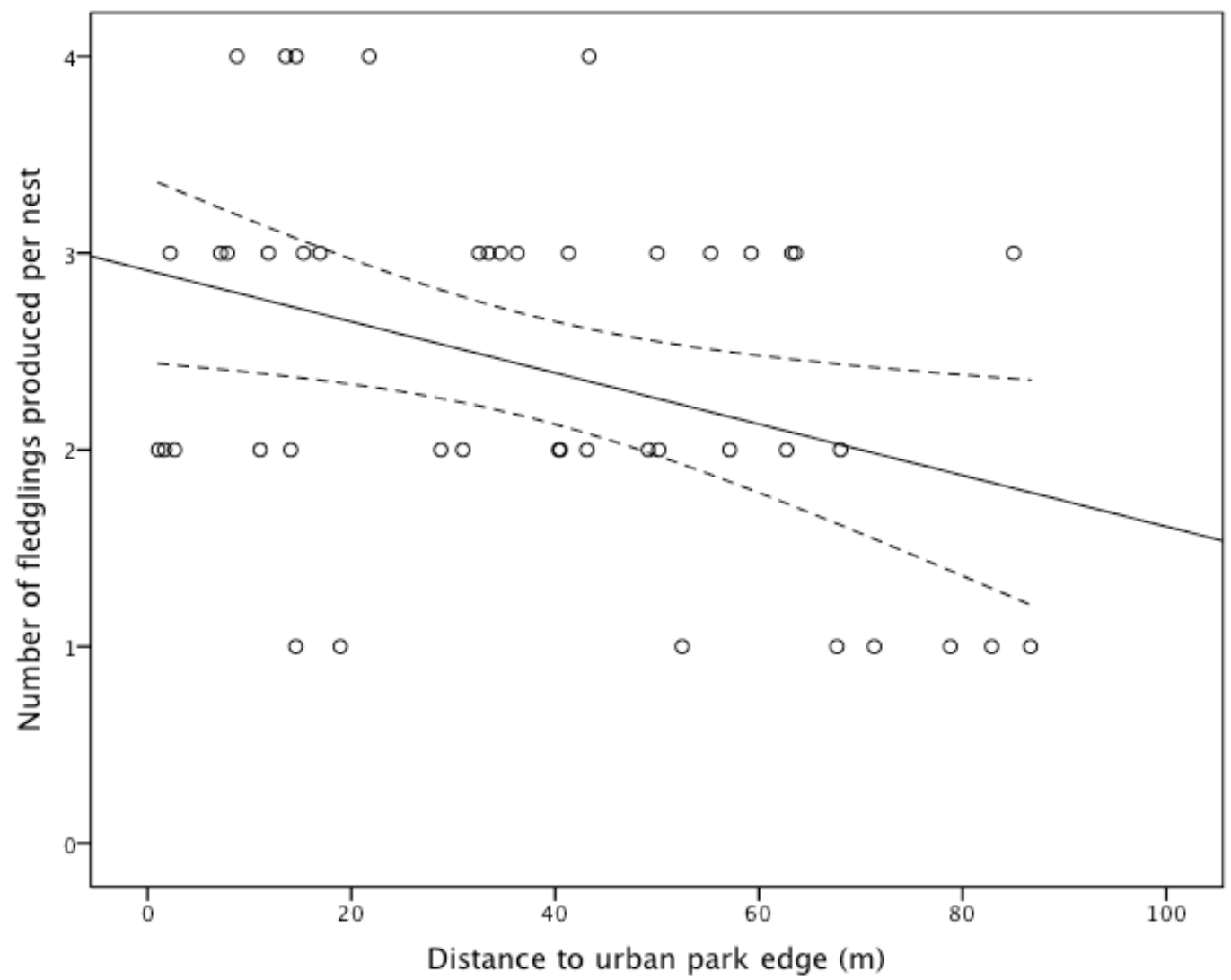

FIG. 2.2. The relationship between the number of Spotted Towhee fledglings produced per nest and the distance from the nest to the nearest edge in an urban park in Lake Oswego, Oregon, 2008-2009. Dashed lines indicate $95 \%$ confidence intervals. 


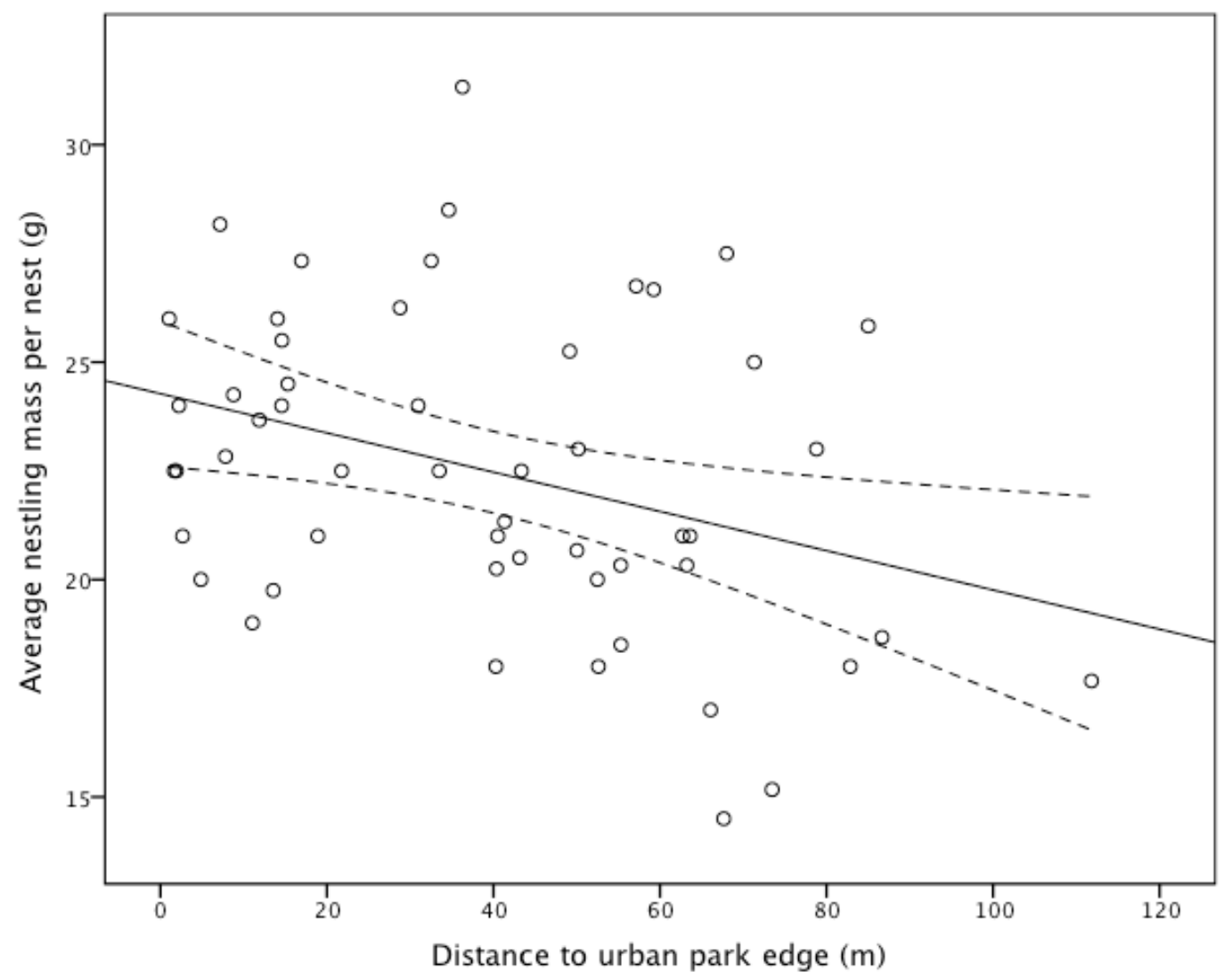

FIG. 2.3. The relationship between average nestling mass just prior to fledging and distance from the nest to the nearest edge in an urban park in Lake Oswego, Oregon, in 2008 and 2009. Dashed lines indicate 95\% confidence intervals. 


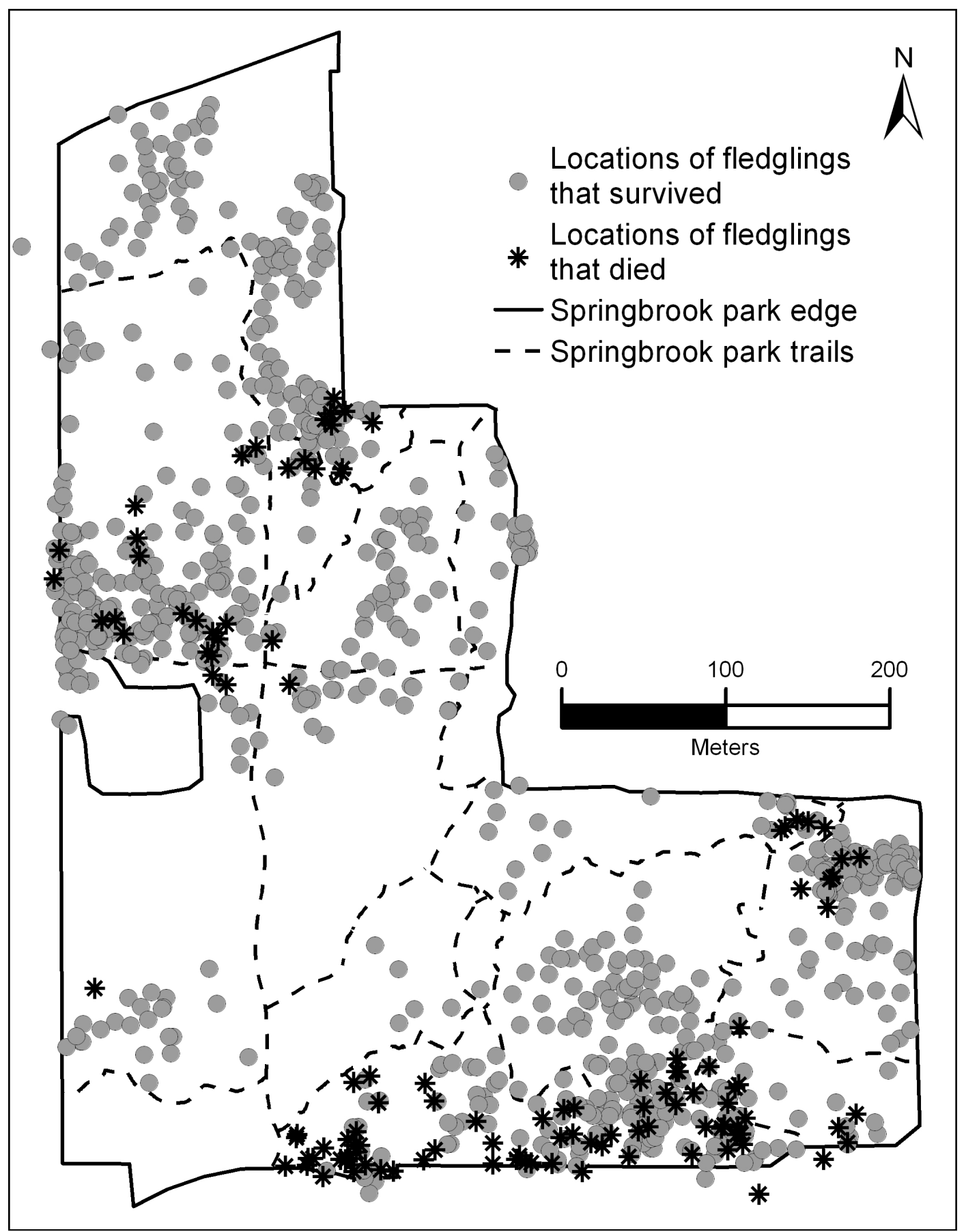

FIG. 2.4. Daily radio telemetry locations of all Spotted Towhee fledglings that survived the postfledging period and that died during the postfledging period in an urban park in Lake Oswego, Oregon, 2008-2009. 


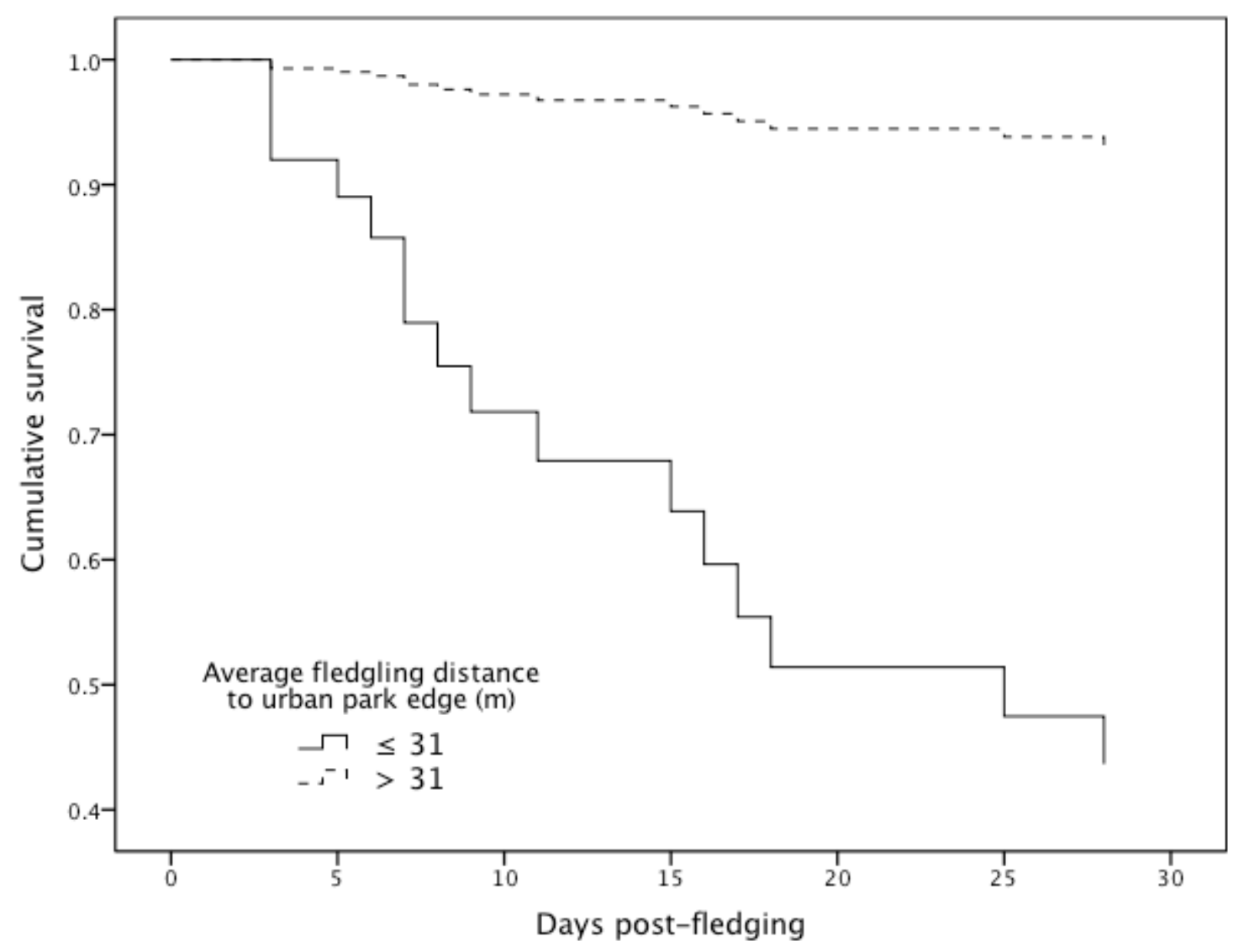

FIG. 2.5. Cox proportional hazards regression for Spotted Towhee fledglings above and below the median fledgling distance to edge in an urban park in Lake Oswego, Oregon, 2008-2009. 


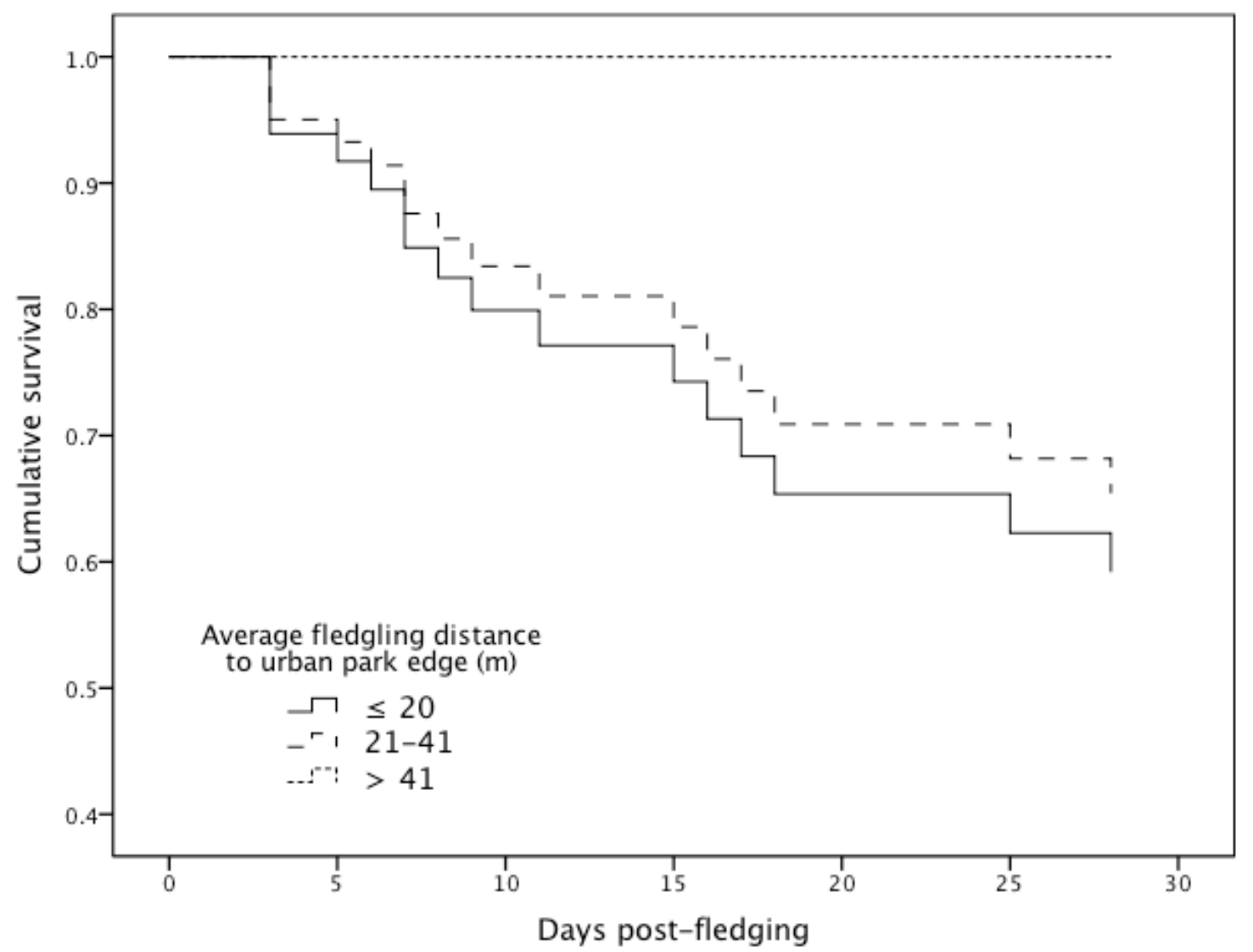

FIG. 2.6. Cox proportional hazards regression for Spotted Towhee fledglings within the lower $25 \%$, middle $50 \%$, and upper $25 \%$ fledgling distance to edge categories in an urban park in Lake Oswego, Oregon, 20082009. 


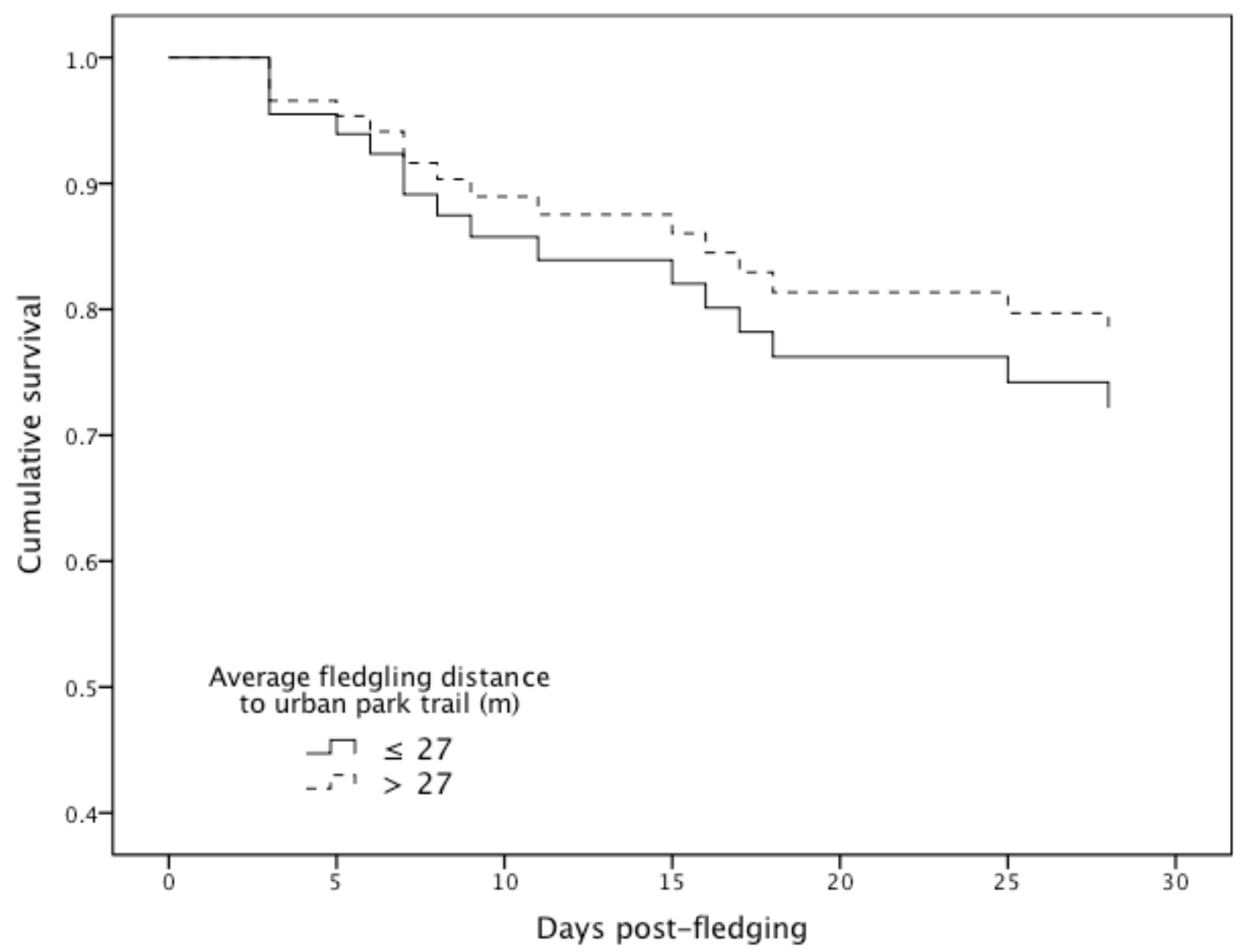

FIG. 2.7. Cox proportional hazards regression for Spotted Towhee fledglings above and below the median fledgling distance to trail in an urban park in Lake Oswego, Oregon, 2008-2009. 


\section{ChaPTER 3: Habitat use of postfledging Spotted Towhees (Pipilo maculatus) in an urban park}

\section{INTRODUCTION}

Urban expansion and the resulting loss and fragmentation of habitats have important effects on birds that range from declines in food availability (Burke and Nol 1998, Bolger et al. 2000, Zanette et al. 2000, Luck 2003), to increases in predation

pressure (Andrén et al. 1985, Yahner 1988, Yahner and Scott 1988, Andrén 1992), noise exposure (Fernández-Juricic et al. 2005), light pollution (Miller 2006), and presence of non-native plant species (Beissinger and Osborne 1982, Marzluff 2001).

As urbanization is on the rise in many parts of the world and is expected to continue (United Nations 2010a, 2010b), an emerging question in need of answer is whether urban parks and greenspaces can function as quality habitats for birds. Measurement of habitat quality is difficult, but a commonly used proxy is reproductive success of the organisms utilizing the habitat. However, the vast majority of studies of reproductive success have measured nest success only (e.g. Morrison and Bolger 2002, Patten and Bolger 2003), and whether this is sufficient is unclear. Only recently have researchers begun to investigate survival of young during the immediate postfledging period. It is unknown to what extent postfledging survival contributes to overall reproductive success and population dynamics (Tarof et al. 2011).

Recently, studies of the postfledging period of parental dependence have become more common in grasslands and habitats fragmented by agriculture or logging. The use of small radio transmitters has made it possible to follow young and often crypticallycolored birds (e.g. Cohen and Lindell 2004, Berkeley et al. 2007, Moore et al. 2010). 
Even fewer data exist for this potentially critical period for birds in urban areas (but see Whittaker and Marzluff 2009, Balogh et al. 2011, Ausprey and Rodewald 2011). Increased presence of predators in urban areas (Jokimäki and Huhta 2000, Haskell et al. 2001), including introduced predators such as domestic cats (Felis domesticus; Crooks and Soulé 1999, Baker et al. 2005), may result in an unnaturally high mortality rate of recently fledged birds (Balogh et al. 2011).

In addition to changes in predation pressure, the habitats in urban areas may be altered as a result of human activity or the introduction of invasive plants. Habitat structure at the nest site has often been studied in relation to nest success in both natural (e.g., Holmes et al. 1996, Matsuoka et al. 1997, Misenhelter and Rotenberry 2000) and urban environments (e.g., Jokimäki and Huhta 2000, Patten and Bolger 2003), but studies of fledgling habitat use are rare, particularly in urban areas. In more natural areas, fledgling and juvenile birds have been found in areas that differ in vegetation structure or composition from that of the nest site (Vega Rivera et al. 1998, White et al. 2005, Rush and Stutchbury 2008), and these differences have also been associated with fledgling survival (King et al. 2006). Habitat requirements of a species may be broader than current studies indicate if birds use different habitats for nesting than they use for the care of fledged young. For example, Rush and Stutchbury (2008) found that habitat used by fledgling Hooded Warblers (Wilsonia citrina) was more structurally complex and had more dense vegetation 2 to $4 \mathrm{~m}$ from the ground than nest site habitat. Likewise, Ovenbird (Seiurus aurocapillus) fledgling habitat had fewer large trees and had greater vertical structure between 0 and $3 \mathrm{~m}$ from the ground than nest habitat (King et al. 2006). It would seem likely that birds in urban areas would behave similarly, but it is unclear 
whether taxonomically and structurally altered urban plant communities provide the full range of habitats needed by breeding birds. Indeed, the increased presence of invasive plant species in urban areas can create ecological traps for nesting birds (Rodewald et al. 2010). On the other hand, invasive plants may not influence fledgling survival (Ausprey and Rodewald 2011).

The Spotted Towhee (Pipilo maculatus) is a resident ground-nesting and groundforaging inhabitant of early successional forests of the Pacific Northwest (Greenlaw 1996). Towhees are also common in urban parks and greenspaces, and recent work on towhees in parks of Portland, Oregon, suggest that populations in some parks are sufficiently productive to be self-sustainable (S. Bartos Smith, unpubl. data). However, like nearly all birds, very little is known about postfledging survival and habitat use of juvenile towhees.

The generally high abundance and activity of predators near habitat edges (Donovan et al. 1997, Heske et al. 1999, Bolger 2002) suggests that Spotted Towhees should avoid park edges. However, both Bartos Smith et al. (2011) and I (Chapter 2) showed that in Portland, OR, Spotted Towhee nests near park edges produced significantly more and heavier young than nests in the interior of parks. Additionally, Bartos Smith et al. (2011) found that the earliest breeding females nested near edges. These data suggested that habitat edges are attractive to towhees possibly because food is more abundant near edges than in the habitat interior, and that food availability overrode possible influences of predators on decisions about where to nest. Despite the apparent preference for edges, I also showed (Chapter 2) that Spotted Towhee fledglings found near edges were more likely to be depredated during the postfledging period. As a 
consequence, although more towhee fledglings were produced from nests near edges, fewer of the young that fledged from nests near edges survived to independence. Edges thus likely represent an ecological trap for towhees (Chapter 2).

Fledgling and juvenile birds are often found in habitats that have relatively dense vegetation (e.g. Jones and Bock 2005, Berkeley et al. 2007, Vitz and Rodewald 2010, Mitchell et al. 2010). Habitat edges have been cited as having complex vegetation that may be beneficial to wildlife (Yahner 1988). Caplan and Yeakley (2006) found that invasive Himalayan Blackberry stands were tallest in areas with the least canopy cover, presumably because the high light environment of edges promotes dense growth of exotic vegetation such as Himalayan Blackberry. Conceivably, the reason why edges function as ecological traps for towhees may be that both predators and towhee fledglings seek the dense cover provided by exotic vegetation.

I conducted a two-year study of the reproductive ecology of Spotted Towhees at a residential park in the Portland, Oregon, metropolitan region. My objectives were to (1) describe habitat structure and vegetation composition within the park in order to determine (2) if vegetation density, plant species composition and diversity (including native vs. non-native), and habitat structure differed among random locations and locations used by towhees for nesting and care of fledged young, and (3) whether either nest success or fledgling survival were associated with the vegetation composition, plant species diversity, and habitat structure. 


\section{Methods}

Study site.- Springbrook Park is a 24-ha urban park located near the border of Lake Oswego and Portland, Oregon, and is one of the four parks included in Bartos Smith et al.'s (2011) study. The park is bordered on the north side by a four-lane road, on the east side by a grass covered athletic field, and on the west and south sides by residential backyards. The canopy is dominated by Bigleaf Maple (Acer macrophyllum), Paper Birch (Betula papyrifera), and Red Alder (Alnus rubra). Douglas Fir (Pseduotsuga menziesii) is locally common in portions of the park. The understory is generally dense and includes an abundance of native species including Sword Fern (Polystichum munitum), Salal (Gaultheria shallon), Indian-Plum (Oemleria cerasiformis), Dull Oregon-Grape (Mahonia nervosa), Beaked Hazelnut (Corylus cornuta), and Thimbleberry (Rubus parviflorus). Non-natives are also common, and the main species are Himalayan Blackberry (Rubus armeniacus), English Ivy (Hedera helix), and English Holly (Ilex aquifolium). English Holly is spread fairly evenly throughout the park. By contrast, Himalayan Blackberry and English Ivy tend to be concentrated in large patches, and since 2003 a neighborhood association has attempted to remove both from the park. The Spotted Towhee population in Springbrook Park was continuously monitored between 2004 and 2009 (Bartos Smith et al. 2011). Typically, 25 to 30 towhee pairs defend territories in the park.

Nest location and transmitter attachment. - Towhees will attempt to raise 2 to 3 broods per year. In 2008 and 2009, I attempted to locate all nests in the park by visiting the park daily beginning in late March and continuing through August. To facilitate nest finding and ensure complete coverage, I captured and marked as many unmarked adult 
towhees as possible. Males were captured using a recording of a towhee song played near a taxidermic mount that was set behind a mist-net in the male's territory. To avoid nest abandonment by adult females, I delayed capturing females until their young were $\geq$ 7 days old. Captures were made by playing a recording of a fledgling towhee distress call near a mist-net. After capture, adults were banded with an aluminum U.S. Fish and Wildlife Service leg band and a unique combination of three colored leg bands. Adults were released at the capture site.

To find towhee nests, I observed female behavior (e.g., collecting nest material during nest construction and extended stationary behavior during incubation). Parental behavior (e.g., defensive behavior and carrying food) was used to find nests with hatched young. Locations of all nests were marked using a Garmin 72 (Garmin Ltd.) global positioning unit that was usually accurate to $<10 \mathrm{~m}$. I visited nests and recorded contents every three days, and banded young 7 days after they hatched. To determine age at fledgling (usually day 10 or 11 post-hatch), I checked nests daily after banding nestlings. Spotted Towhees fledge prematurely if nestlings are handled after day 8 post-hatch (A. A. Shipley, pers. observ.), and an earlier study indicated that attaching transmitters to 7-8 day old nestlings often proved fatal. Therefore, to ensure that the young were large enough to safely carry radio transmitters to monitor their habitat use, I delayed transmitter attachment until three days after young had left the nest. I then captured 1 or 2 fledglings from each brood and fitted them with a Holohil BD-2 radio transmitter with a figure-eight leg harness (Rappole and Tipton 1991). All transmitters and harnesses were $\leq 5 \%$ of fledgling body mass as recommended by Cochran (1980). Fledglings moved relatively little soon after leaving the nest, and I was able to capture them either by hand 
or with a butterfly net after chasing them over the ground for short distances. Even after postponing transmitter attachment until three days post-fledge, some fledglings still did not meet the minimum mass requirement and had to be released without a transmitter.

Radio-tracking.- - I used an FM100 receiver and a three-element folding Yagi antenna (Advanced Telemetry Systems) to locate all radio-tagged fledglings each day between 0700 and 1900 PST until they reached 30 days post-fledge. Fledglings stay with and largely depend on their parents for food and protection during this period (Greenlaw 1996, A. A. Shipley, pers. observ.). Tracking also ended at 30 days post-fledging because the transmitter battery life was only $\sim 50$ days, and I needed to collect transmitters for future use. The sequence in which I tracked fledglings each day was random, and I only approached fledglings as close as necessary to determine identity and location. I avoided pushing fledglings away from where I found them. After locating a fledgling, I marked its location with a flag and a GPS unit (Garmin 72, Garmin Ltd.). To remove transmitters from surviving fledglings at the end of the tracking period, my assistants and I "herded" each offspring into a long line of mist-nets, or by occasionally using mist-nets at night to capture fledglings.

I used ArcGIS 9.2 (ESRI) to project the GPS coordinates of nests and daily fledgling locations onto a map. Random locations were generated in ArcGIS using the Create Random Points tool. I used data collected with a Trimble GPS unit (J. E. McKay, unpubl. data) to project the park perimeter onto the map. Finally, I used the Near Tool in ArcGIS to calculate the shortest distance from each nest, every fledgling location, and all random locations to the nearest park edge. 
Habitat measurements. - To measure habitat variables, I conducted vegetation surveys at nest locations, fledgling locations, and random locations. Vegetation surveys were only conducted for locations where fledglings were found during the first two weeks post-fledging. Fledglings older than this were much more likely to fly greater distances when approached, and I felt that the vegetation where I ultimately found them during these last two weeks may have been influenced by my presence.

I used a 2-meter tall, 3-cm diameter PVC pole marked at 20-cm intervals to measure the vertical structure of the vegetation (adapted from Wiens 1969). Each survey began at the center point, which was at the nest cup for nest locations, at the flag I had placed where each fledgling was found daily for fledgling locations, and at the randomly generated GPS coordinates. I placed the PVC pole vertically at the center point and noted the species of plants that touched the pole at every $20-\mathrm{cm}$ interval. I then stood at the center point and viewed the canopy through a 4-cm diameter cardboard tube to estimate the percentage of canopy cover $(1=0-20 \%, 2=20-40 \%, 3=40-60 \%, 4=60-80 \%$, or $5=$ $80-100 \%$ of the sky obscured by canopy). This entire procedure was repeated 1,2 , and 3 $\mathrm{m}$ from the center point in each of the cardinal directions (13 points for every survey). Because the 2-m PVC pole had ten 20-cm intervals, each plant species had a possible maximum count of 130 per survey. All dead sticks, branches or logs that touched the pole were recorded as "Dead Wood". Dead leaves that touched the pole were recorded as “Dead Leaves". The 13 canopy measurements were averaged to characterize canopy cover ("Canopy") at each point. I created three new variables to encompass all of the vegetation density: "Low density" is the number of $20-\mathrm{cm}$ intervals between the ground and $1 \mathrm{~m}$ above ground at which any vegetation, dead wood, or dead leaves made contact 
with the pole (maximum count possible $=65$ ). "High density" is the same as the former, but between $1 \mathrm{~m}$ and $2 \mathrm{~m}$ above ground, and "Total density" is the sum of Low and High density (maximum possible count $=130$ ). "Total Natives" and "Total NonNatives" are sums of the counts of the abundance of the native and non-native species at each point (excluding dead leaves and dead wood). I used Simpson's index of diversity (Simpson 1949) to calculate an index of plant species diversity ("Diversity"; excluding dead leaves and dead wood), for each point. To explore possible relationships between individual plant species and fledgling habitat use, I selected the 10 most abundant plant species (dead leaves and dead wood were included) found touching the pole during all surveys. All other plant species were observed so infrequently (recorded in $<7 \%$ of all surveys) compared to the top 10 that it was unlikely they were of ecological significance for fledgling towhees.

Statistical Analyses. - To calculate daily nest survival rates, I used Mayfield logistic regression to account for exposure time. The vegetation surveys of the different locations used by a fledgling were averaged so that each fledgling had only a single set of measurements to characterize its habitat use. To condense habitat variables and provide a synthetic description of habitat structure, I conducted a Principal Component Analysis (PCA) based on a correlation matrix that included the log-transformed counts (maximum of 130 per survey before log-transformation) of the 10 most common plant species, as well as the structural habitat variables: Canopy, Low density, High density, Total density, Total Natives, Total Non-Natives, and Diversity. For further analysis, I selected only the principal components (PC) with eigenvalues greater than 1, and only used variables with factor loadings with an absolute value greater than 0.3 to interpret each $\mathrm{PC}$ axis 
(McGarigal et al. 2000). I used linear regression to test for relationships between each PC and distance to the nearest park edge. I then compared each PC among nest, fledgling and random locations using one-way ANOVAs. Finally, for each component, I used twosample $t$-tests to compare successful and unsuccessful nests and fledglings that survived the tracking period and those that died.

\section{RESUlts}

Nest and fledgling survival.- I located 73 Spotted Towhee nests in Springbrook Park during $2008(\mathrm{~N}=27)$ and $2009(\mathrm{~N}=46)$. Fourteen nests in 2008 and 31 nests in 2009 were successful, yielding daily survival rates of 0.9582 (2008) and 0.9680 (2009). Assuming a 27-day period of nest occupancy (egg 1 to fledging), nest success was $31.6 \%$ $(95 \% \mathrm{CI}=12.1 \%$ to $53 \%)$ in 2008 and $41.6 \%(95 \% \mathrm{CI}=22.3 \%$ to $59.7 \%)$ in 2009. Combining years, an average of $37.5 \%$ of nests fledged young $(95 \% \mathrm{CI}=23.1 \%$ to 51.7\%). I radio-tracked 52 fledglings from 35 broods until death or the end of the 30-day postfledging period. Seventeen broods had two transmittered fledglings, and 18 broods had just one. Thirty-six fledglings (69.2\%) survived the actual 27-day tracking period (i.e., days 4 to 30 ; daily survival rate, $S,=0.986$ ), but after applying a correction for the probable number to die in the first three days out of the nest, my adjusted estimate of fledgling survival to 30 days was $62.1 \%$.

Habitat characteristics. - I conducted vegetation surveys at 68 nests, 282 fledgling locations (representing 46 fledglings, which had an average of 6.1 [range: 1-12] surveys each), and 48 random locations. The 10 most common plant species or substrates recorded during the vegetation surveys were (in decreasing order of abundance): Dead 
Leaves, Sword Fern, English Ivy, English Holly, Himalayan Blackberry, Dead Wood, Beaked Hazelnut, Snowberry (Symphoricarpos albus), Indian-Plum, and Salal. The PCA yielded five PC with eigenvalues $>1$, and they accounted for $66.8 \%$ of the variation in the habitat structure measured in Springbrook Park (Table 3.1). The first PC separated habitat on the basis of overall vegetation density, such that sites with positive scores on PC1 were characterized by high vegetation density at all levels (low, high, and total), an abundance of both native and non-native species, and abundant dead leaves and wood, English Ivy, Himalayan Blackberry, English Holly, and native Beaked Hazelnut, IndianPlum, and Snowberry. Variation on PC1 was unrelated to distance to park edge (Fig. 3.1A). The second PC separated habitat based primarily on the abundance of native and non-native plant species. Negative scores described sites dominated by non-natives (especially English Ivy and Himalayan Blackberry) that were closer to the park edge. Sites with positive scores contained mainly native species (particularly hazelnut, Salal and Sword Fern), were relatively diverse, and were distant from the park edge (Fig 3.1B). The third PC separated habitat on the basis of relative height of dense vegetation, with sites with positive scores being characterized by diverse and dense high vegetation (particularly dead wood and Indian-Plum). These sites were also close to the park edge. Sites with negative scores had considerable dense low vegetation (particularly dead leaves and Sword Fern) and were farther from the edge (Fig. 3.1C). PC4 provided a contrast of the distribution of primarily non-native species. Canopy cover and diversity increased along PC4, but sites with negative scores had considerable Himalayan Blackberry but little English Ivy or English Holly. Sites with positive scores had the opposite combination and tended to be far from the park edge (Fig. 3.1D). Positive PC5 
scores described sites that were relatively diverse, had abundant Snowberry, but little dead leaves, dead wood, English Holly, or Salal. PC5 was independent of distance to park edge (Fig. 3.1E).

Habitat characteristics of random sites, and nest and fledgling locations.Scores of nests on PC1 were significantly higher than those of random points, while scores of fledgling locations on PC1 exceeded both random and nest locations (Table 3.2, Fig. 3.2). In other words, habitat at random points, nest sites, and fledgling locations represented a gradient of increasing vegetation density, presence of dead leaves and wood, and abundance of most plant species. Random points on PC2 were intermediate to the locations of nests and fledglings, and did not significantly differ from either (Table 3.2, Fig. 3.2). However, fledgling and nest locations differed, with nests being found in areas dominated by native plant species whereas fledglings were found mainly in areas where non-native plants were most abundant (Fig. 3.2). The latter corresponded also to sites near the park edge (Fig. 3.1). Habitat at nest sites and random locations was again similar along the axis described by PC3 (Fig. 3.2). Nests were placed in habitats with much dense low structure associated with Sword Fern, but low diversity and little dead wood. By contrast, fledglings occupied sites with considerable high structure (especially Indian-Plum), much dead wood, and higher overall diversity, but little low structure or Sword Fern (Table 3.2; Fig. 3.2). Sites with the latter habitat characteristics tended to be found near the park edge (Fig. 3.1).

Habitat at nest and fledgling locations on PC4 was very similar, but both differed from random locations (Fig. 3.2). In comparison to random locations, habitat at nests and fledgling locations had more Himalayan Blackberry, but less canopy cover and little 
English Ivy or English Holly. Finally, random sites and fledgling locations were similar on PC5, but random sites and nest locations differed substantially (Table 3.2; Fig. 3.2). Nests were located in areas with generally high diversity and an abundance of Snowberry, but little in the way of dead matter, English Holly, or Salal. In contrast, random locations had little diversity, but were characterized as having relatively more dead leaves, dead wood, English Holly and Salal. Fledgling locations tended to be intermediate and differed marginally from nest sites.

Habitat, nest success, and fledgling survival. - Comparison of the scores of successful and failed nests on the five PC axes failed to detect any habitat features that were associated with the probability of success (Table 3.2). However, the probability of nest survival declined seasonally (see above), as did nest scores on PC3 $(r=-0.423, \mathrm{~N}=$ $68, P<0.001)$ and PC5 $(r=-0.237, \mathrm{~N}=68, P=0.052)$. I therefore used the logistic exposure model to control for nest exposure time and the date that a nest was found to reexamine the relationships between probability of nest success and vegetation structure as described by the PC axes. Of the five regressions, probability of nest success was most strongly associated with PC4, but it was not significant (coefficient $[\beta]=0.264, \mathrm{SE}=$ $0.202, P=0.191)$.

Direct comparisons of habitat used by fledglings in the first two weeks postfledging also failed to detect a relationship between habitat and whether or not a fledgling survived the postfledging observation period (Table 3.2). Distance to park edge and fledge date, however, were shown previously to be important predictors of fledgling survival, and as described above, 3 of 5 PC axes varied significantly with distance from the edge of the park. Nestlings' body mass at banding also varied with date; a significant 
polynomial relationship existed between mass and date to indicate that the heaviest nestlings fledged during the middle of the breeding season $\left(P\right.$ for date and date ${ }^{2}=0.038$ and 0.030 , respectively; $r^{2}=12.9 \%$ ). Therefore, for the 46 fledglings with data on habitat use, I used logistic regression to examine the probability of fledgling death in relation to distance to park edge, distance to trail, date (and its quadratic), nestling body mass and tarsus length at banding, and the five PC axes. The probability of survival declined with both proximity to park edge $(\beta=-0.073, \mathrm{SE}=0.034, P=0.032)$ and date of banding $(\beta=$ $-0.044, \mathrm{SE}=0.019, P=0.019)$. After controlling for the two latter effects, the next strongest association with fledgling survival was with proximity to trails $(\beta=-0.089, \mathrm{SE}$ $=0.048, P=0.062)$; fledglings far from trails had a tendency towards higher survival. With only distance to park edge and date in the model, the strongest association with the habitat axes was with PC5, but it did not approach significance $(P=0.275)$.

\section{DisCUSSION}

Towhee nest success was moderate, with almost $40 \%$ of nests fledging young over both years. Just over $60 \%$ of fledglings survived the parental dependence period. My data also indicate that nest and fledgling habitat usually differed, and that there were consistent and often considerable differences between habitats used by towhees for nesting and the habitats used by young after they left the nest. Habitat used by fledglings was much more structurally dense than nest site habitat, and fledgling habitat had a greater abundance of non-native plant species than nest site habitat. However, none of the habitat characteristics measured predicted either nest success or fledgling survival. 
Nest and fledgling habitat characteristics and survival. - Habitat at towhee

nest sites and at sites used by fledgling towhees differed in important ways, the most prominent of these being vegetation density. Fledglings used habitat that had denser vegetative cover between 0 and $2 \mathrm{~m}$ above ground than nests, and nests likewise had denser vegetation than random locations. Other research has shown that recently fledged birds often use denser vegetation or areas with higher amounts of shrub cover than both random/unused locations (Jones and Bock 2005, King et al. 2006, Mitchell et al. 2010, Ausprey and Rodewald 2011) and nest sites (Jones and Bock 2005, King et al. 2006, Rush and Stutchbury 2008, Ausprey and Rodewald 2011). Vega Rivera et al. (1998) showed that habitats into which juvenile Wood Thrushes dispersed had a denser understory than natal site habitat. While towhee fledgling habitat was denser overall than both nest and random locations, towhee fledgling locations had more dense high vegetation and were closer to the park edge. Nest and random locations had more dense low vegetation and were farther from the edge. Because towhees are ground-nesters, denser ground-level vegetation may be of value in concealing nests from predators. Young towhees are uncoordinated and vulnerable when they first leave the nest. The availability of concealing vegetation close to (but off of) the ground may be attractive to fledglings and enable them to make short hops and flights from the ground up into the higher vegetation where they may find refuge from ground predators such as domestic cats, snakes, raccoons (Procyon lotor), and chipmunks (Tamias sp.).

Although dense vegetation characterized both towhee nest sites and fledgling locations, neither nest success nor fledgling survival were influenced by vegetation density. The moderate to high rates of nest loss (31\% and 41\% in 2008 and 2009, 
respectively) in my study may be a consequence of either a diverse set of nest predators or an abundance of only a few species of nest predators. If the former, each predator species may favor searching for nests in different locations. For instance, nest predators that locate nests by visual (i.e., avian) and olfactory (i.e., mammalian) means eliminate the possibility that a single optimal location may exist. If the latter, a single abundant nest predator species may, by sheer numbers alone, cause widespread failure and make it difficult to detect associations between nest success and habitat. By contrast to my study, most others that have found differences in vegetation density or shrub cover between nests and fledglings also found that increased vegetation density was positively associated with fledgling survival (King et al. 2006, Vitz and Rodewald 2010, and Ausprey and Rodewald 2011; but see Braden et al. 1997 and Moore et al. 2010). The absence of any apparent benefits of using dense vegetation for towhees may have been nullified by high rates of predation close to park edges. Distance to park edge is an important predictor of fledgling survival (Chapter 2) and much of the vegetation near edges was dense and high. Additionally, I have no knowledge of the type of vegetation that fledglings were actually using when they were killed, or the type(s) of vegetation used by domestic cats (Felis domesticus) and Western Screech-owls (Megascops kennicottii), the two main predators of fledgling towhees (Chapter 2). On the three principal components that showed significant differences between nest sites and random locations, failed nests tended to be located in habitat with vegetation characteristics that more closely resembled random locations than habitat used for nesting. Perhaps if nest success had been higher, vegetation characteristics may have played a significant role in predicting nest success. 
In addition to denser vegetation, locations used by towhee fledglings generally had less diverse vegetation and more non-native plant species (particularly Himalayan Blackberry, English Ivy, and English Holly) than nest sites. These three invasive, nonnative species were important components of the habitat throughout Springbrook Park, and were the only plant species to have factor loadings $>0.300$ on three of the five principal components. Extremely dense "walls" of Himalayan Blackberry may provide very good protection from predators for fledgling birds. On several occasions I attempted, but failed, to capture fledglings near chain-link fences surrounded by 2 to 3 -meter wide walls of blackberry vines on the edge of the park because fledglings simply hopped through holes in the fence. Even in the absence of a fence, it seems probable that dense blackberry patches provide excellent cover from both avian and mammalian predators. Himalayan Blackberry had negative factor loadings on both PC2 and PC4, which both had direct relationships with distance to edge. Thus, Himalayan Blackberry tended to be located closer to park edges. As noted in Chapter 2, fledglings tend to be found close to park edges. It is unclear whether Himalayan Blackberry may be an attractive refuge for fledglings, enticing them closer to dangerous park edges, or if fledglings' proximity to park edges is driven by an ecological trap created by towhee parents' possible attraction to abundant food resources near edges (Chapter 2).

While Himalayan Blackberry was only associated with habitat close to park edges, English Ivy was associated with the park edge on PC2 and the park interior on PC4. PC4 described a habitat gradient whereby sites were dominated by either a high abundance of English Ivy and English Holly, or Himalayan Blackberry alone. The positive association of PC4 with distance to edge indicated that blackberry declined, but 
ivy and holly increased from the edge to the park interior. It appears that parents avoid ivy and holly dominated interior habitat for nesting, and that fledgling towhees spend little time in such sites. English Ivy may not be suitable for nesting (towhee nests were never found completely surrounded by English Ivy) because large "carpets" of English Ivy are usually only 15-20 centimeters tall, and ivy usually excludes virtually all other plant species that provide more cover (Reichard 2000, Vidra et al. 2006), such as Sword Fern and Salal. The general openness of this type of ivy-dominated habitat may be particularly dangerous for young towhees to fly through if avian predators are present. Additionally, towhees forage on the ground by scratching through leaf litter, and horizontally dense mats of English Ivy may eliminate access to leaf litter and may also impede the movements of very young flightless fledglings (A. A. Shipley, pers. observ.). In addition to Himalayan Blackberry, English Holly may also provide dense, protective, usable cover for fledgling towhees. In some cases (PC4), towhees seemed to avoid English Holly altogether, but in others (PC5), fledgling habitat had more English Holly than nest sites. This seeming contradiction may be explained by the presence of English Ivy. Fledglings are not likely to be found in habitat that has both English Holly and large amounts of unusable English Ivy (PC4), which usually occurs far from the park edge. If a fledgling were to be found in a habitat dominated by English Ivy and English Holly, it would doubtless seek cover in the holly. However, when English Holly is associated with plants such as Salal and dead leaves for parental foraging (i.e., PC5), and holly is not associated with the park interior, fledglings are more likely to use this type of habitat and take advantage of English Holly's sharp, dense leaves as cover from predators. 
While fledgling towhee locations tended to have more non-native vegetation than nest sites, neither nest success nor fledgling survival were influenced by the abundance of non-native vegetation. Fledgling habitat use as it relates to native and nonnative vegetation has rarely been studied. Ausprey and Rodewald (2011) found that Northern Cardinal (Cardinalis cardinalis) fledglings were found in habitats with significantly more non-native Amur honeysuckle (Lonicera maackii) than random locations. However, cardinal fledglings also used complex understory vegetation. In this case, cardinal fledgling survival was associated with complex vegetation, but not specifically with honeysuckle. Similarly, towhees use non-native Himalayan Blackberry and English Holly more as fledglings than they do as adults for nesting. This may be because blackberry and holly also happen to be very dense sources of cover, and the attraction is the dense vegetation rather than the particular plant species.

While fledgling towhee locations had denser vegetation than both nest and random locations, and fledgling habitat had more non-native vegetation than nest sites, none of the habitat variables measured influenced fledgling survival. As shown in Chapter 2, distance to park edge was a very important predictor of fledgling survival: fledglings closer to park edges were more likely to die during the postfledging period. It is possible that distance to edge overwhelms all other possible factors that may influence fledgling survival. Perhaps in larger parks, with lower proportions of edge habitat, differences in habitat used by fledglings and that of nest sites may actually translate into improved fledgling survival, as shown by other studies.

This study confirms the results of others that fledglings often use habitat that is very different from that of the nest site, and that fledglings' habitat needs should be 
considered in addition to the habitat requirements of nesting birds when making management decisions. This study is among the first to demonstrate that some non-native plant species may not adversely affect fledgling survival (Ausprey and Rodewald 2011). Some non-native plant species may provide suitable protection from predators for fledglings. However, non-native plant species differ widely in their suitability for both nest placement and fledgling use, and should be carefully considered when prioritizing non-native species removal and native plant restoration.

Park edge, vegetation, and fledgling survival. — As shown in Chapter 2, fledgling survival decreased with increasing proximity to an edge. The mechanism behind this relationship was not clear. I suspected that an increased rate of predation or an increased abundance of predators close to edges was creating this edge effect, but I could not rule out the possibility that habitat characteristics were driving the relationship. For example, if vegetation composition near edges differed from that of the park interior such that fledglings were not able to conceal themselves adequately from predators, then differences in vegetation would likely be responsible for decreased fledgling survival, not an increase in predators near edges. In this chapter, I presented evidence that three of the five habitat PC axes did, in fact, vary with distance to park edge. However, after controlling for distance to park edge, none of the vegetation characteristics were significant predictors of fledgling survival. Thus, while the vegetation does vary with distance to edge, it does not influence fledgling survival, and the edge effect cannot be attributed to changes in vegetation. Because $100 \%$ of fledgling mortality was attributed to predators, an increased rate of predation near edges remains the most likely mechanism for the edge effect experienced by fledgling towhees. 
TABLES AND FIGURES

TABLE 3.1. Principal components for habitat variables measured during vegetation surveys of Spotted Towhee nest locations, Spotted Towhee fledgling locations, and random locations in an urban park in Lake Oswego, Oregon, 2008-2009. Habitat variables with factor loadings in bold are considered with each component in further analyses.

\begin{tabular}{lrrrrr}
\hline & PC1 & PC2 & PC3 & PC4 & PC5 \\
\hline \% Variance Explained & 22.8 & 16.5 & 12.6 & 8.6 & 6.3 \\
Cum. \% Variance Explained & 22.8 & 39.3 & 51.9 & 60.5 & 66.8 \\
Eigenvalue & 3.878 & 2.811 & 2.135 & 1.468 & 1.064 \\
Canopy & -0.026 & 0.287 & 0.091 & $\mathbf{0 . 5 7 9}$ & -0.223 \\
Low density & $\mathbf{0 . 7 6 9}$ & 0.019 & $\mathbf{- 0 . 5 1 2}$ & -0.087 & 0.011 \\
High density & $\mathbf{0 . 7 3 9}$ & -0.011 & $\mathbf{0 . 4 6 9}$ & -0.052 & -0.062 \\
Total density & $\mathbf{0 . 9 4 9}$ & 0.009 & -0.162 & -0.092 & -0.022 \\
Total Natives & $\mathbf{0 . 3 7 8}$ & $\mathbf{0 . 7 7 7}$ & $\mathbf{- 0 . 3 1 5}$ & -0.098 & 0.191 \\
Total Non-Natives & $\mathbf{0 . 5 2 8}$ & $\mathbf{- 0 . 7 5 3}$ & -0.032 & 0.223 & -0.008 \\
Diversity & 0.087 & $\mathbf{0 . 3 0 2}$ & $\mathbf{0 . 3 8 6}$ & $\mathbf{0 . 3 9 3}$ & $\mathbf{0 . 5 0 2}$ \\
(ln)Dead Leaves & $\mathbf{0 . 5 1 3}$ & 0.081 & $-\mathbf{0 . 3 4 0}$ & -0.051 & $\mathbf{- 0 . 3 0 3}$ \\
(ln)Dead Wood & $\mathbf{0 . 4 4 5}$ & 0.162 & $\mathbf{0 . 4 8 7}$ & -0.232 & $\mathbf{- 0 . 3 7 6}$ \\
(ln)English Ivy & $\mathbf{0 . 3 2 9}$ & $\mathbf{- 0 . 5 8 0}$ & -0.225 & $\mathbf{0 . 4 9 7}$ & 0.250 \\
(ln)Himalayan Blackberry & $\mathbf{0 . 3 1 1}$ & $\mathbf{- 0 . 4 4 9}$ & 0.210 & $\mathbf{- 0 . 5 7 2}$ & 0.140 \\
(ln)English Holly & $\mathbf{0 . 4 6 9}$ & -0.096 & 0.257 & $\mathbf{0 . 4 1 9}$ & $\mathbf{- 0 . 3 6 5}$ \\
(ln)Beaked Hazelnut & $\mathbf{0 . 3 0 7}$ & $\mathbf{0 . 5 3 4}$ & 0.234 & 0.052 & 0.143 \\
(ln)Indian-Plum & $\mathbf{0 . 3 7 9}$ & 0.054 & $\mathbf{0 . 5 1 9}$ & 0.171 & 0.133 \\
(ln)Salal & -0.176 & $\mathbf{0 . 5 6 2}$ & 0.187 & 0.037 & $\mathbf{- 0 . 3 2 0}$ \\
(ln)Snowberry & $\mathbf{0 . 4 1 9}$ & 0.283 & 0.248 & -0.187 & $\mathbf{0 . 3 6 2}$ \\
(ln)Sword Fern & 0.284 & $\mathbf{0 . 4 4 8}$ & $\mathbf{- 0 . 6 6 1}$ & 0.158 & 0.022 \\
\hline & & & & &
\end{tabular}


TABLE 3.2. Results of ANOVAs that compared habitats used by Spotted Towhees for nest and fledgling locations, and random locations, and results of $t$-tests that compared successful and failed nest locations and surviving and non-surviving fledgling locations for five principal components that summarize habitat variables.

\begin{tabular}{|c|c|c|c|c|c|}
\hline & $\mathrm{PC} 1$ & $\mathrm{PC} 2$ & $\mathrm{PC} 3$ & PC4 & PC5 \\
\hline Nest Locations & $-0.206 \pm 0.098$ & $0.235 \pm 0.131$ & $-0.235 \pm 0.129$ & $-0.170 \pm 0.126$ & $0.278 \pm 0.132$ \\
\hline $\begin{array}{l}\text { Fledgling } \\
\text { Locations }\end{array}$ & $0.929 \pm 0.080$ & $-0.232 \pm 0.134$ & $0.455 \pm 0.095$ & $-0.161 \pm 0.143$ & $-0.164 \pm 0.120$ \\
\hline $\begin{array}{l}\text { Random } \\
\text { Locations }\end{array}$ & $-0.599 \pm 0.141$ & $-0.112 \pm 0.132$ & $-0.103 \pm 0.153$ & $0.395 \pm 0.125$ & $-0.237 \pm 0.137$ \\
\hline ANOVA & $\begin{array}{c}\mathrm{F}=46.993 \\
\boldsymbol{P}<\mathbf{0 . 0 0 1}\end{array}$ & $\begin{array}{l}\mathrm{F}=3.524 \\
\boldsymbol{P}=\mathbf{0 . 0 3 2}\end{array}$ & $\begin{array}{l}F=7.464 \\
P=\mathbf{0 . 0 0 1}\end{array}$ & $\begin{array}{l}F=5.617 \\
P=\mathbf{0 . 0 0 4}\end{array}$ & $\begin{array}{l}\mathrm{F}=4.797 \\
\boldsymbol{P}=\mathbf{0 . 0 0 9}\end{array}$ \\
\hline \multicolumn{6}{|l|}{ Post-Hoc Tests } \\
\hline $\begin{array}{l}\text { Nests vs. } \\
\text { Random }\end{array}$ & $P=0.027$ & $P=0.151$ & $P=0.747$ & $P=0.007$ & $P=0.016$ \\
\hline $\begin{array}{l}\text { Nests vs. } \\
\text { Fledglings }\end{array}$ & $P<0.001$ & $P=\mathbf{0 . 0 3 7}$ & $P=0.001$ & $P=0.999$ & $P=0.050$ \\
\hline $\begin{array}{l}\text { Fledglings vs. } \\
\text { Random }\end{array}$ & $P<0.001$ & $P=0.826$ & $P=0.015$ & $P=0.017$ & $P=0.931$ \\
\hline Successful Nests & $-0.197 \pm 0.117$ & $0.164 \pm 0.176$ & $-0.139 \pm 0.173$ & $-0.248 \pm 0.163$ & $0.353 \pm 0.171$ \\
\hline Failed Nests & $-0.221 \pm 0.176$ & $0.359 \pm 0.189$ & $-0.401 \pm 0.186$ & $-0.035 \pm 0.200$ & $0.148 \pm 0.209$ \\
\hline $\begin{array}{l}t \text {-test for Nest } \\
\text { Fate }\end{array}$ & $\begin{array}{l}t=-0.116 \\
P=0.908\end{array}$ & $\begin{aligned} t & =0.717 \\
P & =0.476\end{aligned}$ & $\begin{array}{l}t=-0.982 \\
P=0.329\end{array}$ & $\begin{array}{l}t=0.811 \\
P=0.420\end{array}$ & $\begin{array}{l}t=-0.746 \\
P=0.459\end{array}$ \\
\hline $\begin{array}{l}\text { Fledgling } \\
\text { Survivors }\end{array}$ & $0.945 \pm 0.099$ & $-0.203 \pm 0.172$ & $0.412 \pm 0.111$ & $-0.180 \pm 0.182$ & $-0.276 \pm 0.137$ \\
\hline $\begin{array}{l}\text { Fledgling Non- } \\
\text { survivors }\end{array}$ & $0.890 \pm 0.132$ & $-0.305 \pm 0.191$ & $0.566 \pm 0.183$ & $-0.110 \pm 0.217$ & $0.121 \pm 0.229$ \\
\hline $\begin{array}{l}t \text {-test for } \\
\text { Fledgling Fate }\end{array}$ & $\begin{array}{l}t=-0.307 \\
P=0.760\end{array}$ & $\begin{array}{l}t=-0.341 \\
P=0.735\end{array}$ & $\begin{array}{c}t=0.732 \\
P=0.468\end{array}$ & $\begin{array}{c}t=0.218 \\
P=0.829\end{array}$ & $\begin{array}{c}t=1.513 \\
P=0.138\end{array}$ \\
\hline
\end{tabular}

Principal component values for 68 nests ( 43 successful and 25 failed), 46 fledglings (33 survivors and 13 non-survivors), and 48 random locations were included in these analyses. Values given are means $\pm \mathrm{SE}$. There were $2 \mathrm{df}$ for ANOVAs, $66 \mathrm{df}$ for Nest Fate $t$-tests, and $44 \mathrm{df}$ for Fledgling Fate $t$-tests. 
A

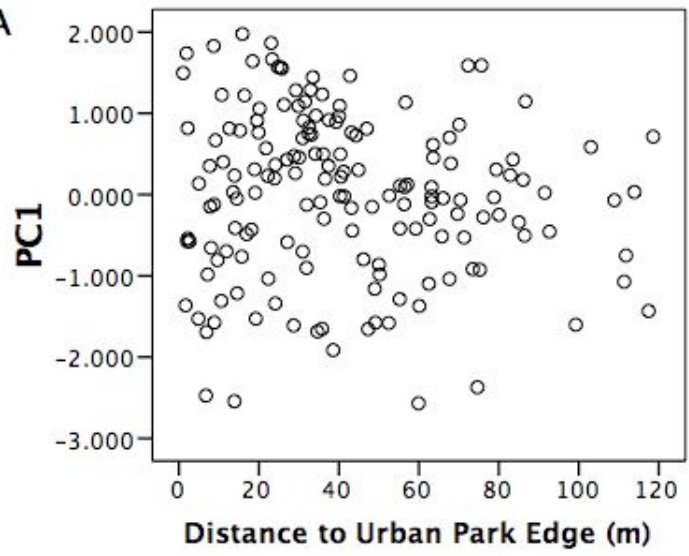

C

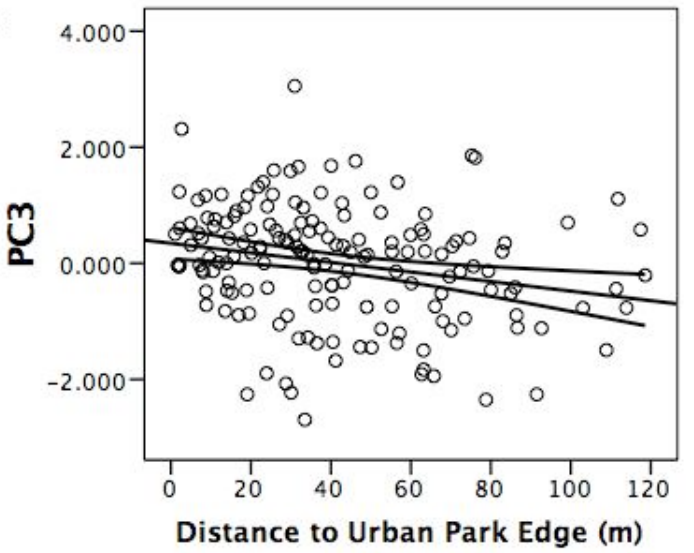

$E$

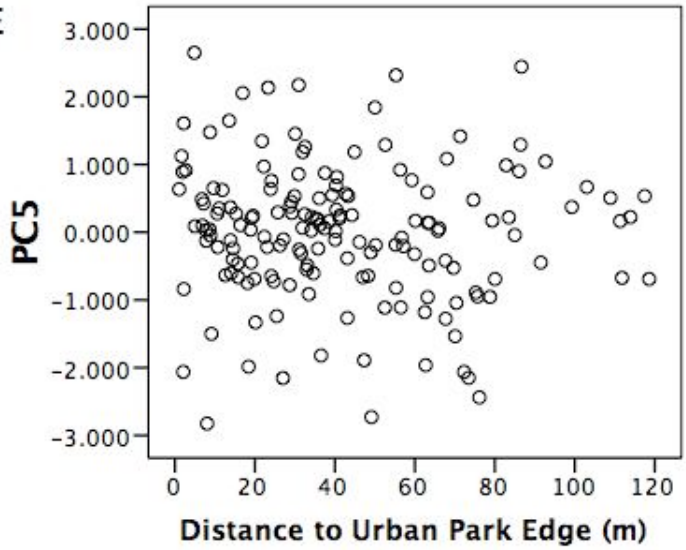

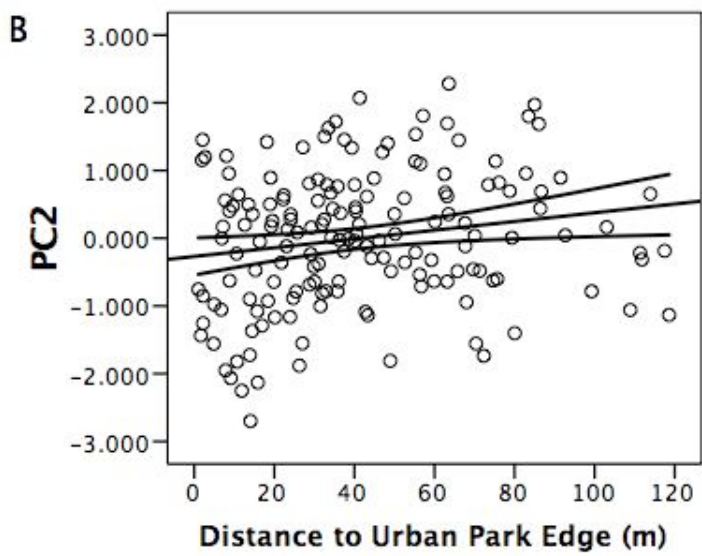

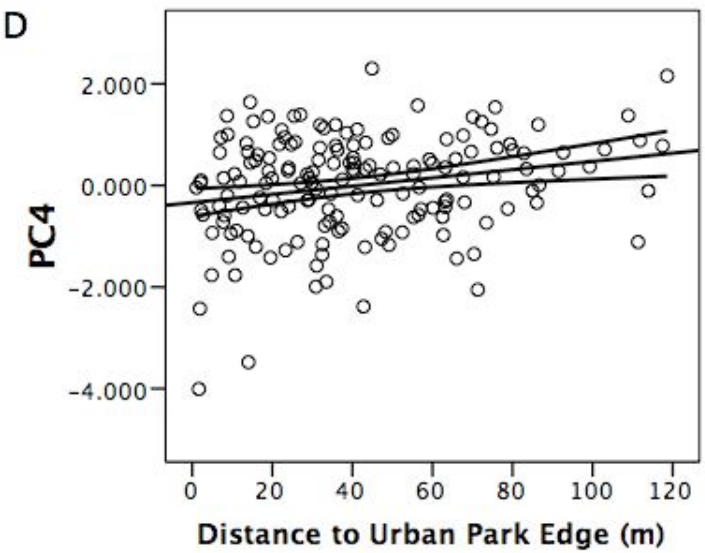

FIG. 3.1. The relationships between five principal components that summarize habitat variables and distance to the nearest edge in an urban park in Lake Oswego, Oregon, 2008-2009. (A) $\beta=-0.004 \pm 0.003$, $t=-1.310, \mathrm{df}=160, P=0.192$. (B) $\beta=0.006 \pm 0.003, t=2.336, \mathrm{df}=160, P=0.021$. (C) $\beta=-0.008 \pm$ $0.003, t=-3.014, \mathrm{df}=160, P=0.003$. (D) $\beta=0.008 \pm 0.003, t=2.964, \mathrm{df}=160, P=0.003$. (E) $\beta=-0.002$ $\pm 0.003, t=-0.852, \mathrm{df}=160, P=0.396$. Curved lines indicate $95 \%$ confidence intervals. 

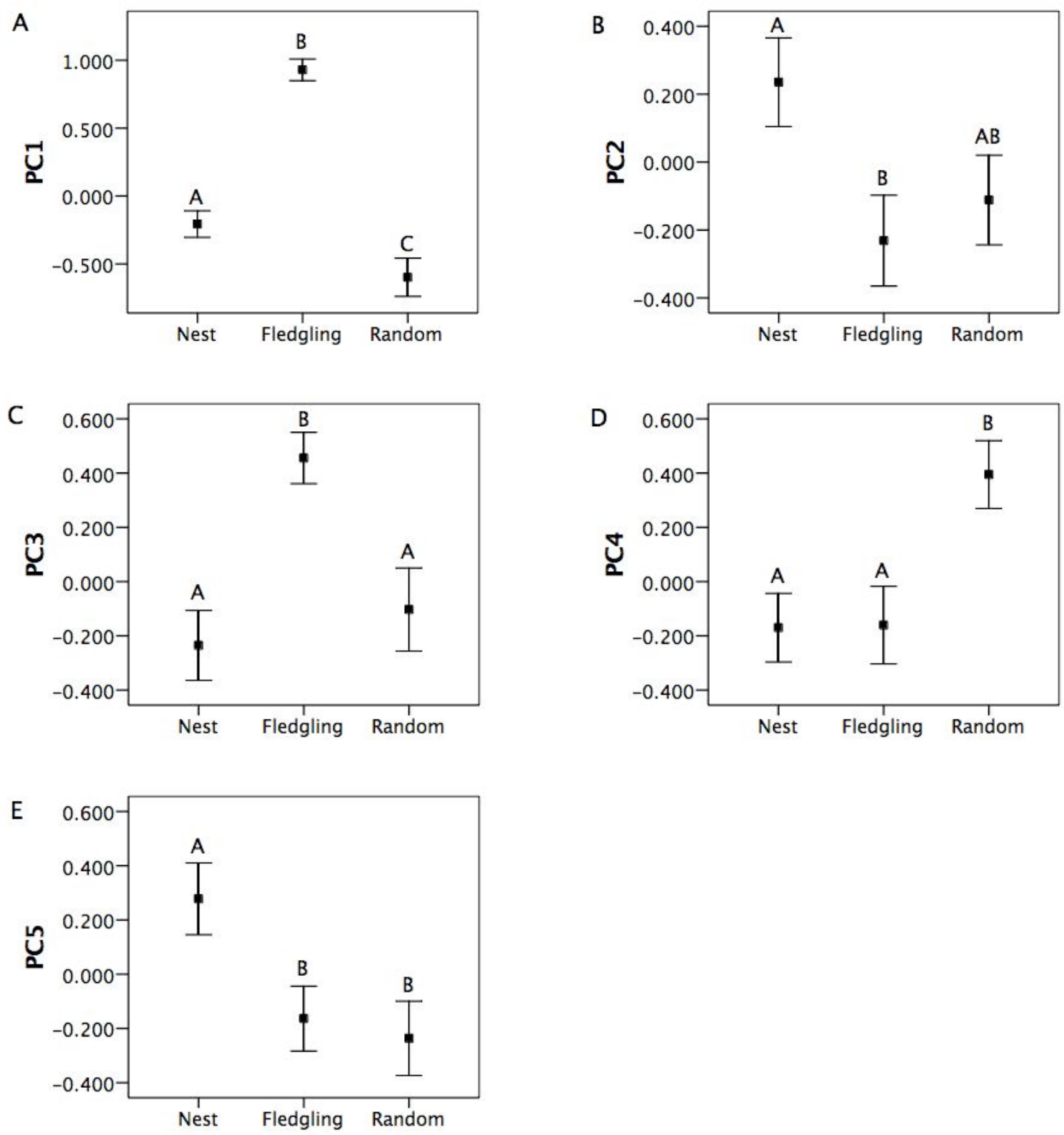

FIG. 3.2. Mean values of principal components 1-5 for Spotted Towhee nest and fledgling locations, and random locations in an urban park in Lake Oswego, Oregon, 2008-2009. (A) Locations with high PC1 values had denser vegetation between 0-2 m from the ground than locations with low PC1 values. (B) Locations with high PC2 values had more native vegetation (particularly Beaked Hazelnut, Salal, and Sword Fern) and less non-native vegetation (particularly English Ivy and Himalayan Blackberry), and were more diverse than locations with low PC2 values. (C) Locations with high PC3 values had less dense low vegetation, had more dense high vegetation, and had fewer total natives, but were more diverse than locations with low PC3 values. (D) Locations with high PC4 values had greater canopy cover, more English Ivy and English Holly, but less Himalayan Blackberry, and were more diverse than locations with low PC4 values. (E) Locations with high PC5 values were more diverse, had more Snowberry, and had less abundant dead leaves, dead wood, Salal, and English Holly than locations with low PC5 values. A, B, C coding indicates significant differences at the $\alpha=0.05$ level. Error bars represent SE. 


\section{Chapter 4: Conclusions}

In Chapter 2, I showed (and corroborated the results of Bartos Smith et al. 2011) that towhee nests near park edges produced more and heavier fledglings than nests in the park interior. While this shows that edges are not inherently poor habitat and may be associated with increased food resources, any benefits towhees may have gained by nesting near edges were reversed during the postfledging period. Fledglings that were often found near edges (and that spent more time outside of the park) were more likely to die during the first 30 days out of the nest than fledglings found deeper in the park. Domestic cats and Western Screech-owls were implicated as major predators of fledglings. This apparent preference for nesting near edges, combined with high mortality during the postfledging period, indicates a particularly deceptive (for researchers) ecological trap. The vast majority of research conducted on birds to determine habitat needs ends after young leave the nest. By this measure, edges would be deemed good habitat for towhees. Only after following fledglings was I able to see that edge habitat can be detrimental overall to towhee populations. This highlights the importance of not placing undue weight on nesting habitat when evaluating a species' habitat needs.

In Chapter 3, I presented evidence that fledglings use habitat that has vegetation characteristics that are different than those found at both towhee nest sites and random locations in the park. In particular, fledgling towhees used habitat that was significantly more structurally dense than both nests and random locations. This denser vegetation may provide fledglings with an important source of protection from predators. In addition, fledglings used habitat that had significantly more non-native vegetation, particularly Himalayan Blackberry and English Holly, than nest sites. Himalayan 
Blackberry was also associated with habitat near the park's edge. English Ivy seemed to be completely unusable for towhees, and neither towhee nests nor fledglings were likely to be found in it. Additionally, while towhees may select nest sites that are close to edges because they are attracted to abundant food resources, the increased presence of dense Himalayan Blackberry cover near edges may encourage towhees to remain near edges with their fledglings, even though edges ultimately proved dangerous for fledglings. The presence of Himalayan Blackberry near edges may increase the attractiveness of the habitat, potentially adding to the severity of this ecological trap for towhees.

While fledgling habitat differed from that of nest sites and random locations in the park, vegetation characteristics did not influence either nest success or fledgling survival. Three of the five habitat PC axes varied with distance to edge, but after controlling for distance to edge, the habitat variables did not influence fledgling survival. Therefore, the edge effect experienced by fledgling towhees is directly attributable to increased rates of predation near edges, presumably because of greater predator abundance or activity, and is not an artifact of differences in habitat composition near edges.

Together, these two chapters provide important new information about how birds use habitat in urban areas and how they are affected by changes in predation pressure, introduced species, and increasing edge habitat resulting from fragmentation. The results of both chapters highlight the importance of taking into consideration more than one stage of the life cycle of a species when determining its habitat needs.

Increased predation of fledglings near edges, particularly by cats, contributes to high fledgling mortality and may limit the potential for urban parks and greenspaces to 
function as sources instead of sinks and provide quality habitat for birds. The combination of increased habitat attractiveness, possibly created by backyard birdfeeders, and the increased presence of domestic cats (often in the same backyard) may create an exceptionally deadly situation for young birds. Additionally, the spread of non-native invasive plant species may be eliminating habitat needed by both nesting and fledgling birds.

Several management strategies could be utilized to maximize the potential for urban parks to provide quality habitat for birds. To limit the numbers of young birds killed by domestic cats, public education should be a priority. Keeping cats inside, particularly during the spring and summer months (May-August) when fledglings are about, should be emphasized. While giving birds supplemental food may be beneficial (for both humans and birds), having both birdfeeders and outdoor cats in the same backyard or area should be strongly discouraged.

In many areas where Himalayan Blackberry, English Ivy, and English Holly are a problem, efforts are being made by various groups and organizations to remove these invasive species and restore native vegetation. Based on my results, English Ivy removal should be prioritized over the removal of Himalayan Blackberry and English Holly. While ivy seemed to be completely useless for both nest sites and fledgling habitat, blackberry and holly could at least provide protective cover for fledglings. Removing ivy from urban parks and planting native vegetation in its place may drastically increase the amount of quality habitat that is available to birds away from dangerous park edges. In some areas, holly was often found interspersed with ivy. When removing the ivy, holly trees could be left intact and removed after native vegetation had replaced the ivy. This 
would provide temporary "islands" of cover that fledglings could utilize when moving through the park.

My results hint at various directions for future study. In particular, it would be useful to replicate this study in another species that uses birdfeeders and has vulnerable fledglings. When cats are present at edges, I predict that a similar ecological trap would manifest for other bird species. It may also be interesting to replicate this study in parks with and without coyotes. Coyotes may limit cat numbers, and thus fledgling survival may improve with a greater number of coyotes. Finally, to determine if birdfeeders contribute to the creation of an ecological trap by attracting towhees to park edges, birdfeeders could be placed at regular intervals throughout the park, beginning in the winter (well before nest sites are chosen). If this experiment were to be conducted, I predict that (1) there will be no association between park edge and nest placement, (2) the number of fledglings produced per nest will not be related to distance to park edge, (3) nestlings will not be heavier near park edges, (4) fledgling survival will still be lowest near park edges, but (5) the overall fledgling survival rate for the park will be higher. More study could further elucidate the effects of providing supplemental food to birds, continue to help us understand how our actions affect bird and other animal populations, and provide additional ideas for how to make parks and greenspaces more suitable habitat. 


\section{REFERENCES}

Anders, A. D., D. C. Dearborn, J. FAaborg, And F. R. Thompson III. 1997. Juvenile survival in a population of neotropical migrant birds. Conservation Biology 11:698707.

ANDRÉN, H. 1992. Corvid density and nest predation in relation to forest fragmentation: a landscape perspective. Ecology 73:794-804.

Andrén, H., P. Angelstam, E. LindSTRÖM, AND P. WidÉn. 1985. Differences in predation pressure in relation to habitat fragmentation: an experiment. Oikos 45:273277.

AusPREY, I. J. AND A. D. RodeWALD. 2011. Postfledging survivorship and habitat selection across a rural-to-urban landscape gradient. The Auk 128:293-302.

Baker, P. J., A. J. Bentley, R. J. Ansell, AND S. HarRis. 2005. Impact of predation by domestic cats Felis catus in an urban area. Mammal Review 35:302-312.

Balogh, A. L., T. B. Ryder, AND P. P. MARRA. 2011. Population demography of Gray Catbirds in the suburban matrix: sources, sinks, and domestic cats. Journal of Ornithology Published online January 2011.

Bartos Smith, S., J. E. MCKAY, AND M. T. MurPhy. 2011. Edges, trails, and reproductive performance of Spotted Towhees in urban greenspaces. Studies in Avian Biology in press.

BEISSINGER, S. R. AND D. R. OSBORNE. 1982. Effects of urbanization on avian community organization. The Condor 84:75-83.

Berkeley, L. I., J. P. Mccarty, AND L. L. Wolfenbarger. 2007. Postfledging survival and movement in Dickcissels (Spiza americana): implications for habitat management and conservation. The Auk 124:396-409.

Blouin-Demers, G. AND P. J. Weatherhead. 2001. Habitat use by Black Rat Snakes (Elaphe obsoleta obsoleta) in fragmented forests. Ecology 82:2882-2896.

Bock, C. E., AND Z. F. JonEs. 2004. Avian habitat evaluation: should counting birds count? Frontiers in Ecology and the Environment 2:403-410.

Bolger, D. T. 2002. Habitat fragmentation effects on birds in Southern California: contrast to the top-down paradigm. Studies in Avian Biology 25:141-157. 
Bolger, D. T., A. V. Suarez, K. R. Crooks, S. A. Morrison, and T. J. Case. 2000. Arthropods in urban habitat fragments in Southern California: area, age, and edge effects. Ecological Applications 10:1230-1248.

Bollinger, E. K., P. B. Bollinger, And T. A. Gavin. 1990. Effects of hay-cropping on eastern populations of the Bobolink. Wildlife Society Bulletin 18:142-150.

Braden, G. T., R. L. McKernan, And S. M. Powell. 1997. Association of withinterritory vegetation characteristics and fitness components of California Gnatcatchers. The Auk 114:601-609.

BRown, W. P. AND R. R. Roth. 2004. Juvenile survival and recruitment of Wood Thrushes Hylocichla mustelina in a forest fragment. Journal of Avian Biology 35:316-326.

Burke, D. M. AND E. NOL. 1998. Influence of food abundance, nest-site habitat, and forest fragmentation on breeding Ovenbirds. The Auk 115:96-104.

Burke, D. M. AND E. Nol. 2000. Landscape and fragment size effects on reproductive success of forest-breeding birds in Ontario. Ecological Applications 10:1749-1761.

CAPLAN, J. S. AND J. A. YEAKLEY. 2006. Rubus armeniacus (Himalayan blackberry) occurrence and growth in relation to soil and light conditions in Western Oregon. Northwest Science 80:9-17.

Chalfoun, A. D., M. J. Ratnaswamy, And F. R. Thompson. 2002. Songbird nest predators in forest-pasture edge and forest interior in a fragmented landscape. Ecological Applications 12:858-867.

Chasko, G. C. And J. E. GATES. 1982. Avian habitat suitability along a transmission-line corridor in an oak-hickory forest region. Wildlife Monographs 82:1-41.

Cochran, W. W. 1980. Wildlife telemetry. Pp. 507-520 In Wildlife Management Techniques Manual (S. D. Schemnitz, ed.). The Wildlife Society, Washington, D.C.

Cohen, E. B. AND C. A. LindelL. 2004. Survival, habitat use, and movements of fledgling White-throated Robins (Turdus assimilis) in a Costa Rican agricultural landscape. The Auk 121:404-414.

CROOKS, K. R., AND M. E. SoulÉ. 1999. Mesopredator release and avifaunal extinctions in a fragmented system. Nature 400:563-566. 
Donovan, T. M., P. W. Jones, E. M. Annand, And F.R. Thompson III. 1997.

Variation in local-scale edge effects: mechanisms and landscape context. Ecology 78:2064-2075.

Fernández-Juricic, E., R. P. Poston, K. Decollibus, T. Morgan, B. Bastain, C. Martin, K. Jones, And R. TReminio. 2005. Microhabitat selection and singing behavior patterns of male House Finches (Carpodacus mexicanus) in urban parks in a heavily urbanized landscape in the Western U.S. Urban Habitats 3:49-69.

Flaspholer, D. J., S. A. Temple, AND R. N. Rosenfield. 2001. Species-specific edge effects on nest success and breeding bird density in a forested landscape. Ecological Applications 11:32-46.

Gates, J. E. AND L. W. Gysel. 1978. Avian nest dispersion and fledging success in field-forest ecotones. Ecology 59:871-883.

Greenlaw, J. S. 1996. Spotted Towhee (Pipilo maculatus). In The Birds of North America, No. 263 (A. Poole and F. Gill, eds.). The Academy of Natural Sciences, Philadelphia, PA, and The American Ornithologists' Union, Washington, D.C.

HASKell, D. G., A. M. KNUPP, AND M. C. SCHNEIDER. 2001. Nest predator abundance and urbanization. Pp. 243-258 In Avian Ecology and Conservation in an Urbanizing World (J.M. Marzluff, R. Bowman, and R. Donnelly, eds.). Kluwer Academic Publishers, Norwell, MA.

HAZLER, K. R. 2004. Mayfield logistic regression: a practical approach for analysis of nest survival. The Auk 121:707-716.

HESKE, E. J. 1995. Mammalian abundances on forest-farm edges vs. forest interiors in southern Illinois: Is there an edge effect? Journal of Mammalogy 76:562-568.

Heske, E. J., S. K. Robinson, AND J. D. Brawn. 1999. Predator activity and predation on songbird nests on forest-field edges in east-central Illinois. Landscape Ecology 14:345-354.

Hinsley, S. A., P. Rothery, AND P. E. Bellamy. 1999. Influence of woodland area on breeding success in Great Tits Parus major and Blue Tits Parus caeruleus. Journal of Avian Biology 30:271-281. 
Holmes, R. T., P. P. MARRA, AND T. W. Sherry. 1996. Habitat-specific demography of breeding Black-throated Blue Warblers (Dendroica caerulescens): implications for population dynamics. Journal of Animal Ecology 65:183-195.

Horváth, G. B. Bernáth, AND G. MolinÁR. 1988. Dragonflies find crude oil visually more attractive than water: multiple-choice experiments on dragonfly polarotaxis. Naturwissenschaften 85:292-297.

Howell, C. A., W. D. DiJAK, AND F. R. ThOMPSON. 2007. Landscape context and selection for forest edge by breeding Brown-headed Cowbirds. Landscape Ecology 22:273-284.

JANSSON, C., J. ECKMAN, AND A. BRÖMSSEN. 1981. Winter mortality and food-supply in tits Parus-spp. Oikos 37:313-322.

Johnson, R. G. AND S. A. TEMPLE. 1990. Nest predation and brood parasitism of tallgrass prairie birds. Journal of Wildlife Management 54:106-111.

JOKIMÄKI, J. AND E. HuHTA. 2000. Artificial nest predation and abundance of birds along an urban gradient. The Condor 102:838-847.

JoNES, Z. F. AND C. E. Bock. 2005. The Botteri's Sparrow and exotic Arizona grasslands: an ecological trap or habitat regained? The Condor 107:731-741.

Kaiser, S. A. AND C. A. Lindell. 2007. Effects of distance to edge and type on nestling growth and nest survival in the Wood Thrush. The Condor 109:288-303.

KERSHNER, E. L. AND E. K. BOLLINGER. 1996. Reproductive success of grassland birds at east-central Illinois airports. American Midland Naturalist 136:358-366.

Kershner, E. L., J. W. Walk, AND R. E. Warner. 2004. Postfledging movements and survival of juvenile Eastern Meadowlarks (Sturnella magnus) in Illinois. The Auk 121:1146-1154.

King, D. I., R. M. DegraAf, M. L. Smith, AND J. P. Buonaccorsi. 2006. Habitat selection and habitat-specific survival of fledgling Ovenbirds (Seiurus aurocapilla). Journal of Zoology 269:414-421.

KolBE, J. J. AND F. J. JANZEN. 2002. Impact of nest-site selection on nest success and nest temperature in natural and disturbed habitats. Ecology 83:269-281. 
Kriska, G., G. Horvath, AND S. AndrikoviCs. 1998. Why do mayflies lay their eggs en masse on dry asphalt roads? Water-imitating polarized light reflected from asphalt attracts Ephemeroptera. Journal of Experimental Biology 201:2273-2286.

LlOYD, J. D. AND T. E. MARTIN. 2005. Reproductive success of Chestnut-collared Longspurs in native and exotic grassland. The Condor 107:363-374.

LUCK, G. W. 2003. Differences in reproductive success and survival of the Rufous Treecreeper (Climacteris rufa) between a fragmented and unfragmented landscape. Biological Conservation 109:1-14.

Manolis, J. C., D. E. Andersen, And F. J. Cuthbert. 2002. Edge effect on nesting success of ground nesting birds near regenerating clearcuts in a forest-dominated landscape. The Auk 119:955-970.

MARTIN, T. E. 1988. Habitat and area effect on forest bird assemblages: is nest predation an influence? Ecology 69:74-84.

MARTIN, T. E. 1993. Nest predation among vegetation layers and habitat types: revising the dogmas. American Naturalist 141:897-913.

MARZLufF, J. M. 2001. Worldwide urbanization and its effects on birds. Pp. 19-47 In Avian Ecology and Conservation in an Urbanizing World (J.M. Marzluff, R. Bowman, and R. Donnelly, eds.). Kluwer Academic Publishers, Norwell, MA.

Marzluff, J. M., J. J. Millspaugh, P. Hurvitz, And M. S. Handcock. 2004. Relating resources to a probabilistic measure of space use: forest fragments and Steller's Jays. Ecology 85:1411-1427.

Matsuoka, S. M., C. M. Handel, D. D. Roby, And D. L. Thomas. 1997. The relative importance of nesting and foraging sites in selection of breeding territories by Townsend's Warblers. The Auk 114:657-667.

McGarigal, K., S. Cushman, And S. StafFord. 2000. Multivariate Statistics for Wildlife and Ecology Research. Springer-Verlag, New York, New York.

MCKinNEY, M. L. 2008. Effects of urbanization on species richness: a review of plants and animals. Urban Ecosystems 11:161-176.

Miller, J. R. And N. Thompson HobBs. 2000. Recreational trails, human activity, and nest predation in lowland riparian areas. Landscape and Urban Planning 50:227-236. 
MiLler, M. W. 2006. Apparent effects of light pollution on singing behavior of American Robins. The Condor 108:130-139.

Miller, S. G., R. L. KNight, AND C. K. Miller. 1998. Influence of recreational trails on breeding bird communities. Ecological Applications 8:162-169.

Misenhelter, M. D. And J. T. Rotenberry. 2000. Choices and consequences of habitat occupancy and nest site selection in Sage Sparrows. Ecology 81:2892-2901.

Mitchell, G. W., P. D. TAYlor, And I. G. WARKentin. 2010. Multiscale postfledging habitat associations of juvenile songbirds in a managed landscape. The Auk 127:354363.

Moore, L., B. J. M. Stutchbury, D. Burke, And K. Elliot. 2010. Effects of forest management on post-fledging survival of Rose-breasted Grosbeaks (Pheucticus ludovicianus). The Auk 127:185-194.

MORRISON, S. A. AND D. T. BOLGER. 2002. Lack of an urban edge effect on reproduction in a fragmentation-sensitive sparrow. Ecological Applications 12:398-411.

MurCIA, C. 1995. Edge effects in fragmented forests: implications for conservation. Trends in Ecology and Evolution 10:58-62.

NAEF-DAEnZER, F. WidMER, AND M. NuBER. 2001. Differential post-fledging survival of Great and Coal Tits in relation to their condition and fledging date. Journal of Animal Ecology 70:730-738.

NiEMUTh, N. D. AND M. S. BoyCE. 1997. Edge-related nest losses in Wisconsin pine barrens. Journal of Wildlife Management 61:1234-1239.

Nussbaum, R. A., E. D. Brodie, JR., AND R. M. Storm. 1983. Amphibians and Reptiles of the Pacific Northwest. The University Press of Idaho, Moscow, Idaho.

Packard, J. M., R. K. Frohlich, J. E. Reynolds, III, And J. R. WilcoX. 1989. Manatee response to interruption of a thermal effluent. Journal of Wildlife Management 53:692-700.

Patten, M. A. And D. T. Bolger. 2003. Variation in top-down control of avian reproductive success across a fragmentation gradient. Oikos 101:479-488.

Pattern, M. A. And J. F. Kelly. 2010. Habitat selection and the perceptual trap. Ecological Applications 20:2148-2156. 
Pulliam, H. R. 1988. Sources, sinks, and population regulation. American Naturalist 132: 652-661.

Pyle, P. 1997. Identification Guide to North American Birds, Part 1: Columbidae to Ploceidae. Slate Creek Press, Bolinas, California.

RAPPOlE, J. H. AND A. R. TIPTON. 1991. New harness design for attachment of radio transmitters to small passerines. Journal of Field Ornithology 62:335-337.

ReICHARD, S. 2000. Hedera helix. Pp. 212-216 In Invasive Plants of California's Wildlands (C. C. Bossard, J. M. Randall, and M. C. Hoshovsky, eds.). University of California Press, Berkeley, CA.

REMES, V. 2003. Effects of exotic habitat on nesting success, territory density, and settlement patterns in the Blackcap (Sylvia atricapilla). Conservation Biology 17:1127-1133.

RICKLEFS, R. E. 1969. An analysis of nesting mortality in birds. Smithsonian Contributions in Zoology 9:1-48.

RIES, L. AND W. F. FAGAN. 2003. Habitat edges as a potential ecological trap for an insect predator. Ecological Entomology 28:567-572.

Ringsby, T. H., B.-E. SÆTher, AND E. J. SOlbERG. 1998. Factors affecting juvenile survival in House Sparrow Passer domesticus. Journal of Avian Biology 29:241-247.

Robertson, B. A. AND R. L. HutTo. 2006. A framework for understanding ecological traps and an evaluation of existing evidence. Ecology 87:1075-1085.

Rodewald, A. D., D. P. Shustack, And L. E. HitchCOCK. 2010. Exotic shrubs as ephemeral ecological traps for nesting birds. Biological Invasions 12:33-39.

Rush, S. A. AND B. J. M. Stutchbury. 2008. Survival of fledgling Hooded Warblers (Wilsonia citrina) in small and large forest fragments. The Auk 125:183-191.

SimpSON, E. H. 1949. Measurement of diversity. Nature 163:688.

Sinclair, K. E., G. R. Hess, C. E. Moorman, And J. H. Mason. 2005. Mammalian nest predators respond to greenway width, landscape context and habitat structure. Landscape and Urban Planning 71:277-293. 
Smith, R. M., K. Thompson, J. G. Hodgson, P. H. Warren, K. J. Gaston. 2006. Urban domestic gardens (IX): Composition and richness of the vascular plant flora, and implications for native biodiversity. Biological Conservation 129:312-322.

St. JoHN, A. 2002. Reptiles of the Northwest. Lone Pine Publishing, Edmonton, Alberta, Canada.

Suedkamp Wells, K. M., M. R. Ryan, J. J. Millspaugh, F. R. Thompson iII, and M. W. HubBARD. 2007. Survival of postfledging grassland birds in Missouri. The Condor 109:781-794.

Sullivan, K. 1989. Predation and starvation: age-specific mortality in juvenile juncos (Junco phaenotus). Journal of Animal Ecology 58:275-286.

Tarof, S. A., P. M. Kramer, J. R. Hill, III, J. Tautin, And B. J. M. Stutchbury. 2011. Brood size and late breeding are negatively related to juvenile survival in a Neotropical migratory songbird. The Auk in press.

United NATiOns. 2010a. The world at six billion. http://www.un.org/esa/population/publications/sixbillion/sixbilpart1.pdf

UNITED NATIONS. 2010b. Urban trends: Urban sprawl now a global problem In UN habitat: State of the world's cities 2010/2011- Bridging the urban divide. http://www.unhabitat.org/documents/SOWC10/R4.pdf

United Nations Population Division. 2011. World Population Prospects: The 2010 Revision. United Nations, New York. http://esa.un.org/unpd/wpp/index.htm

VANCAMP L. F. AND C. J. HENNY. 1975. The screech owl: its life history and population ecology in Northern Ohio. North American Fauna Number 71, United States Department of the Interior Fish and Wildlife Service.

VAn Horne, B. 1983. Density as a misleading indicator of habitat quality. Journal of Wildlife Management 47:893-901.

Vega Rivera, J. H., J. H. Rappole, W. J. McSheA, And C. A. Hass. 1998. Wood Thrush postfledging movements and habitat use in Northern Virginia. The Condor 100:69-78.

ViCKERY, P. D., M. L. HunTER, JR., AND J. V. Wells. 1992. Is density an indicator of breeding success? The Auk 109:706-710. 
VIDRA, R. L., T. H. SHEER, AND T. R. WENTWORTH. 2006. Testing the paradigms of exotic species invasion in urban riparian forests. Natural Areas Journal 26:339-350.

Vitz, A. C. And A. D. Rodewald. 2010. Movements of fledgling Ovenbirds (Seiurus aurocapilla) and Worm-eating Warblers (Helmitheros vermivorum) within and beyond the natal home range. The Auk 127:364-371.

WIENS, J. A. 1969. An approach to the study of ecological relationships among grassland birds. Ornithological Monographs 8:1-93.

Weldon, A. J. AND N. M. HADDAD. 2005. The effects of patch shape on Indigo Buntings: evidence for an ecological trap. Ecology 86:1422-1431.

WhitTAKer, K. A. AND J. M. MARZLUfF. 2009. Species-specific survival and relative habitat use in an urban landscape during the postfledging period. The Auk 126:288299.

White, J. D., T. Gardali, F. R. Thompson III, And J. FAABOrG. 2005. Resource selection by juvenile Swainson's Thrushes during the postfledging period. The Condor 107:388-401.

Wightman, C. S. 2009. Survival and movements of fledgling Western Bluebirds. Southwestern Naturalist 54:248-252.

Yackel Adams, A. A., S. K. Skagen, And R. D. Adams. 2001. Movements and survival of lark bunting fledglings. The Condor 103:643-647.

YAHNER, R. H. 1988. Changes in wildlife communities near edges. Conservation Biology 2:333-339.

YAHNER, R. H. AND D. P. SCOTT. 1988. Effects of forest fragmentation on depredation of artificial nests. The Journal of Wildlife Management 52:158-161.

Zanette, L., P. Doyle, And S. M. Tremont. 2000. Food shortage in small fragments: evidence from an area-sensitive passerine. Ecology 81:1654-1666. 